\title{
On Biophysical Properties and Sensitivity to Gap Junction Blockers of Connexin 39 Hemichannels Expressed in HeLa Cells
}

OPEN ACCESS

Edited by:

Ali Mobasheri,

University of Surrey, UK

Reviewed by:

Richard David Veenstra,

State University of New York Upstate

Medical University, USA

Alonso P. Moreno,

University of Utah, USA

Aida Salameh

Leipzig University, Germany

*Correspondence:

Anibal A. Vargas

anvargas@uc.c

Juan C. Sáez jsaez@bio.puc.cl

Specialty section:

This article was submitted to Membrane Physiology and Membrane

Biophysics,

a section of the journal

Frontiers in Physiology

Received: 16 November 2016

Accepted: 13 January 2017

Published: 09 February 2017

Citation:

Vargas $A A$, Cisterna $B A$, Saavedra-Leiva F, Urrutia $C$, Cea LA, Vielma AH, Gutierrez-Maldonado SE, Martin AJM, Pareja-Barrueto C, Escalona Y, Schmachtenberg $O$ Lagos CF, Perez-Acle T and Sáez JC (2017) On Biophysical Properties and Sensitivity to Gap Junction Blockers of

Connexin 39 Hemichannels Expressed

in HeLa Cells. Front. Physiol. 8:38, doi: 10.3389/fphys.2017.00038
Anibal A. Vargas ${ }^{1 *}$, Bruno A. Cisterna ${ }^{1,2}$, Fujiko Saavedra-Leiva ${ }^{1}$, Carolina Urrutia ${ }^{1}$, Luis A. Cea ${ }^{3}$, Alex H. Vielma ${ }^{2}$, Sebastian E. Gutierrez-Maldonado ${ }^{2,4}$, Alberto J. M. Martin 2,4, Claudia Pareja-Barrueto ${ }^{4}$, Yerko Escalona ${ }^{2,4}$, Oliver Schmachtenberg ${ }^{2}$, Carlos F. Lagos ${ }^{5,6}$, Tomas Perez-Acle ${ }^{2,4}$ and Juan C. Sáez ${ }^{1,2 *}$

${ }^{1}$ Departamento de Fisiología, Pontificia Universidad Católica de Chile, Santiago, Chile, ${ }^{2}$ Centro Interdisciplinario de Neurociencia de Valparaíso, Universidad de Valparaíso, Valparaíso, Chile, ${ }^{3}$ Institute of Biomedical Sciences, Faculty of Medicine, Universidad de Chile, Santiago, Chile, ${ }^{4}$ Computational Biology Lab (DLab), Fundación Ciencia \& Vida, Santiago, Chile, ${ }^{5}$ Department of Endocrinology, School of Medicine, Pontificia Universidad Católica de Chile, Santiago, Chile, ${ }^{6}$ Facultad de Ciencia, Universidad San Sebastián, Santiago, Chile

Although connexins (Cxs) are broadly expressed by cells of mammalian organisms, Cx39 has a very restricted pattern of expression and the biophysical properties of Cx39-based channels [hemichannels (HCs) and gap junction channels (GJCs)] remain largely unknown. Here, we used HeLa cells transfected with Cx39 (HeLa-Cx39 cells) in which intercellular electrical coupling was not detected, indicating the absence of GJCs. However, functional HCs were found on the surface of cells exposed to conditions known to increase the open probability of other $\mathrm{Cx}$ HCs (e.g., extracellular divalent cationic-free solution (DCFS), extracellular alkaline $\mathrm{pH}$, mechanical stimulus and depolarization to positive membrane potentials). Cx39 HCs were blocked by some traditional Cx HC blockers, but not by others or a pannexin1 channel blocker. HeLa-Cx39 cells showed similar resting membrane potentials (RMPs) to those of parental cells, and exposure to DCFS reduced RMPs in Cx39 transfectants, but not in parental cells. Under these conditions, unitary events of $\sim 75$ pS were frequent in HeLa-Cx39 cells and absent in parental cells. Real-time cellular uptake experiments of dyes with different physicochemical features, as well as the application of a machine-learning approach revealed that Cx39 HCs are preferentially permeable to molecules characterized by six categories of descriptors, namely: (1) electronegativity, (2) ionization potential, (3) polarizability, (4) size and geometry, (5) topological flexibility and (6) valence. However, Cx39 HCs opened by mechanical stimulation or alkaline $\mathrm{pH}$ were impermeable to $\mathrm{Ca}^{2+}$. Molecular modeling of Cx39-based channels suggest that a constriction present at the intracellular portion of the para helix region co-localizes with an electronegative patch, imposing an energetic and steric barrier, which in the case of GJCs may hinder channel function. Results reported here demonstrate that $\mathrm{C} \times 39$ form HCs and add to our understanding of the functional roles of $\mathrm{Cx} 39 \mathrm{HC}$ under physiological and pathological conditions in cells that express them.

Keywords: Cx39, gap junction, electrical coupling, membrane potential, unitary conductance, dye-uptake, permeability 


\section{INTRODUCTION}

Connexins (Cxs) are integral membrane proteins expressed in most tissues of vertebrate animals, and are coded in humans by 21 different genes (von Maltzahn et al., 2004). Six similar $\mathrm{Cx}$ subunits form a homomeric hemichannel (HC) and two similar Cx HCs form a homotypic gap junction channel (GJC), which enable communication between the intra and extracellular milieus or the cytoplasm of two adjacent cells, respectively (Sáez et al., 2003).

Cx HCs are involved in autocrine and paracrine cell signaling, because they are non-selective channels permeable to ions and different small molecules, including metabolic substrates and signaling molecules such glucose, $\mathrm{NAD}^{+}$, ATP, glutamate, NO and $\mathrm{PGE}_{2}$ (Bennett et al., 2003; Figueroa et al., 2013; Orellana and Stehberg, 2014). HC activity can be regulated by phosphorylation (Bao et al., 2007; Puebla et al., 2016), redox potential (Contreras et al., 2002; Retamal et al., 2006, 2007), pH (Beahm and Hall, 2002; D'hondt et al., 2013), and other conditions (Sáez et al., 2005). In addition, the open probability of different Cx HCs has been observed to increase in cells exposed to low extracellular $\mathrm{Ca}^{2+}$ concentration (Sáez et al., 2005), positive membrane voltages (Sáez et al., 2005) or mechanical stress (D’hondt et al., 2009), and is drastically reduced by $\mathrm{La}^{3+}$ and GJC blockers such as carbenoxolone (CBX), 18- $\beta$-glycyrrhetinic acid (BGA) and octanol among others (D'hondt et al., 2013). Nonetheless, it remains unknown whether the aforementioned conditions affect Cx39 HCs.

Cx HCs are believed to present low open probability under basal in vitro conditions (Trexler et al., 1996; Kondo et al., 2000; Contreras et al., 2003; Sáez et al., 2005). The range of unitary conductance of $\mathrm{Cx}$ HCs varies between $17 \mathrm{pS}$ in $\mathrm{Cx} 32 \mathrm{HCs}$ (Gómez-Hernández et al., 2003; Oh et al., 2004) to 352 pS in Cx52 HCs (Valiunas and Weingart, 2000). The unitary conductance of Cx HCs is higher than that of Cx GJCs constituted of the same Cx type (Sáez et al., 2005). Specifically, the unitary conductance of homomeric HCs composed of $\mathrm{Cx} 30, \mathrm{Cx} 43$, or $\mathrm{Cx} 45$ is about twice the conductance of homotypic GJCs formed by the same Cx (Valiunas and Weingart, 2000; Valiunas, 2002; Contreras et al., 2003). Since the unitary conductance of Cx39 GJCs has not been described, it is not possible to speculate about the unitary conductance of Cx39 HCs.

The permeability of Cx HCs to molecules has been frequently studied by means of uptake or release of 1 to 3 small molecules including fluorescent dyes with different sizes, shapes and net charges (Schalper et al., 2008), such as ethidium bromide $\left(\mathrm{Etd}^{+}\right)$, $4^{\prime}, 6$-diamidino-2-phenylindole $\left(\mathrm{DAPI}^{+2}\right)$ and Lucifer yellow $\left(\mathrm{LY}^{-2}\right.$ ), among others (Sáez et al., 2005). With these tools, HCs composed of Cx26 (Figueroa et al., 2014), Cx32 (Sánchez et al., 2009), Cx43 (Contreras et al., 2003; Retamal et al., 2007; Orellana et al., 2011) as well as HCs formed by other Cxs described so far present similar permeability features to dyes upon activation with different stimuli. To date, Cx39 HCs express in HeLa cells have been shown to be permeable to $\mathrm{Etd}^{+}$(Cea et al., 2013), but their permeability features remain largely unknown.

Mouse Cx39 shares $\sim 61 \%$ sequence similarity with the human ortholog Cx40.1 and it is transiently expressed in mouse myoblasts during late embryonic development (von Maltzahn et al., 2004), after denervation of adult fast myofibers (Cea et al., 2013), as well as in $m d x$ mouse myofibers (Cea et al., 2016), which is a model of Duchenne's disease. Cx39-deficient mice display accelerated myogenesis and regeneration of skeletal muscles (von Maltzahn et al., 2011). In exogenous expression systems, Cx39 does not form GJCs as determined by dye coupling techniques using a small number of permeability probes (von Maltzahn et al., 2004). However, formation of Cx39 GJCs has not been demonstrated with more sensitive techniques such as electrical coupling measurements.

In 2009, the structure of human Cx26 HCs was solved by X-ray crystallography, showing the formation of hexagonal transmembrane arrangements (Maeda et al., 2009). The HCs dock end-to-end to form an intercellular channel that spans the membrane bilayers of apposed cells and the virtual extracellular gap. Each monomer conformation is comprised of four transmembrane helices (TM1-TM4), in which any pair of adjacent helices are antiparallel, comprises two extracellular loops (E1, E2), one cytoplasmic loop (CL) and N-terminal helix (NTH) located intracellularly. This Cx structure can be studied with comparative modeling techniques (Koehler Leman et al., 2015), so as to gain additional insights into the structure-activity relationships of specific $\mathrm{Cx}$ isoforms and mutants involved in different pathologies (Harris, 2001; Araya-Secchi et al., 2012).

The present study includes functional assays for GJCs and HCs in HeLa cells transfected with Cx39 (HeLa-Cx39). We found that HeLa-Cx39 cells do not form functional GJCs since cells remain electrically uncoupled consistent with structural limitations identified by in silico studies, but present HCs activated by different conditions. These HCs are impermeable to $\mathrm{Ca}^{2+}$ but are permeable to small molecules with no clear preference for negative or positive net charges, and are inhibited by several conventional Cx-based channel blockers, but not others.

\section{MATERIALS AND METHODS}

\section{Reagents}

Octanol, heptanol, carbenoxolone, oleamide, $\mathrm{LaCl}_{3}, \mathrm{Etd}^{+}$, procion orange MX2R, brilliant blue G (BBG), Evans blue, propidium iodide, 4-Bromo calcium ionophore A23187 were purchased from Sigma-Aldrich (St. Louis, Missouri, USA). The 9-amino-6-Chloro-2-Methoxyacridine (ACMA), $\mathrm{DAPI}^{+2}$, hexidium iodide, nuclear yellow, BOBO 1-iodide, 7 aminoactinomycin D (7-ADD), YOYO 1-iodide, TOTO 1-iodide and ethidium homodimer-2-bromide obtained from Invitrogen (Massachusetts, USA), indocyanine green from Pulsion medical systems, (Feldkirchen, Germany) methylene blue from Euromed (Santiago, Chile).

\section{Cell Lines}

HeLa cells were cultured in a DMEM medium supplemented with $10 \%$ fetal bovine serum supplemented with $50 \mathrm{U} / \mathrm{ml}$ of penicillin and streptomycin, at $\mathrm{pH} 7.4$ and kept at $37^{\circ} \mathrm{C}$ in $5 \%$ $\mathrm{CO}_{2} / 95 \%$ air atmosphere. HeLa-Cx39 and HeLa Cx43-EGFP transfected cells were selected with $0.5 \mathrm{mg} / \mathrm{mL}$ of puromycin 
and $0.3 \mathrm{mg}$ of geneticin (Invitrogen, MA, USA), respectively, as described previously (Jordan et al., 1999; von Maltzahn et al., 2004). The Hela-Cx39 cells were kindly provided by Dr. Klaus Willecke, Lymes Institute, University of Bonn, Bonn, Germany. For each experiment, cells were seeded on glass coverslips, until appropriate confluence was reached. Cells were always fed the day before an experiment.

The Cx39 transfection was confirmed by immunofluorescence. In brief, cells on glass coverslips, were washed with PBS, and fixed with formaldehyde $4 \%$ and incubated with blocking solution (1\% BSA, $0.025 \%$ triton X-100 and $50 \mathrm{mM}$ $\mathrm{NH}_{4} \mathrm{Cl}$, in PBS, at $\mathrm{pH} 7.4$ ) overnight. Then, cells were incubated with rabbit anti-Cx39 antibody (Invitrogen, MA, USA) for $6 \mathrm{~h}$ at room temperature, washed with PBS and incubated 30 min with secondary rabbit anti-IgGs (Santa Cruz, Texas, USA) conjugated to $\mathrm{Cy} 2$ or $\mathrm{Cy} 3$. Preparations were subsequently washed with PBS, and coverslips were mounted with fluoromont $\mathrm{G}$ (Electron Microscopy Science, PA, USA).

\section{Electrophysiology}

Functional HCs were evaluated in whole-cell voltage clamp experiments as previously described (Sánchez et al., 2009). The bath solution contained: (in mM) $140 \mathrm{NaCl}, 5.4 \mathrm{CsCl}, 1 \mathrm{MgCl}_{2}$, $1.8 \mathrm{CaCl}_{2}, 2 \mathrm{BaCl}_{2}$, and $10 \mathrm{HEPES}$ at $\mathrm{pH}$ 7.4. The pipette solution contained (in mM): $130 \mathrm{CsCl}, 10 \mathrm{AspNa}, 0.26 \mathrm{CaCl}_{2}, 1 \mathrm{MgCl}_{2}, 2$ EGTA, 7 TEA-Cl, and 5 HEPES at $\mathrm{pH}$ 7.2. The pipette resistance in the bath was 10-15 $\mathrm{M} \Omega$. All recordings were performed at room temperature $\left(21-23^{\circ} \mathrm{C}\right)$. The microscopic and macroscopic currents were obtained with voltage steps $(+60 \mathrm{mV}$ for $40 \mathrm{~s})$ and ramp protocols $(-80 \mathrm{mV}$ to $+80 \mathrm{mV}$, for $9 \mathrm{~s})$.

Membrane potential (RMP) measurements were performed under a whole-cell current clamp configuration at $37^{\circ} \mathrm{C}$ in individual cells. The pipette solution contained $3 \mathrm{M} \mathrm{KCl}$ and the bath solution contained: (in $\mathrm{mM}$ ) $145 \mathrm{NaCl}, 5 \mathrm{KCl}, 3 \mathrm{CaCl}_{2}$,
$1 \mathrm{MgCl}_{2}, 5$ glucose, 10 HEPES, 5 Tris at $\mathrm{pH}$ 7.4. The pipette resistance in the bath was 30-50 M $\Omega$. The recorded RMP corresponded to the potential value measured when crossing the cell membrane and remained stable for $5 \mathrm{~s}$ after accessing.

For electrical coupling, high density cells cultures (50-70\%) were bathed with a solution containing: (in $\mathrm{mM}$ ) $150 \mathrm{NaCl}, 4 \mathrm{KCl}$, $1 \mathrm{MgCl}_{2}, 1.2 \mathrm{CaCl}_{2}$ and 5 HEPES at $\mathrm{pH}$ 7.4. The pipette solution was the same used in $\mathrm{HC}$ experiments plus $18 \mu \mathrm{M} \mathrm{DAPI}^{+2}$ in one pipette to identify the cell in indirect immunofluorescence for Cx39. The junctional current was recorded in an adjacent cell using voltage steps increasing in $20 \mathrm{mV}$ from -100 to $0 \mathrm{mV}$ and a duration of $200 \mathrm{~ms}$ each. The holding potential of nonstepped cells was $-60 \mathrm{mV}$ and the gap junction conductance $\left(g_{j}\right)$ was calculated from $g_{j}=-I_{b} /\left(V_{a}-V_{b}\right)$, as described previously (Van Rijen et al., 1998). All experiments were done using an Olympus IX 51 inverted microscope with an Axopatch1-D amplifier, Digidata 1322 digitaizer and Clampex 9.1 acquisition software. Data were analyzed with Clampfit 2.1 software (Molecular Devices, CA, USA).

\section{Dye Uptake Assay}

Cells were bathed in same control solution used for RMP experiments, supplemented with $5 \mu \mathrm{M}$ of each dye that does not permeate the cell membrane (Table 1). Cells were recorded $5 \mathrm{~min}$ in control solution, and were then washed 5 times with control solution without $\mathrm{CaCl}_{2}$ and $\mathrm{MgCl}_{2}$ [divalent cation free solution (DCFS)] to promote $\mathrm{HC}$ opening, as shown for other Cx HCs (Cea et al., 2013). Images were recorded every $30 \mathrm{~s}$ for 20 min with a Nikon Eclipse Ti inverted microscope and NISElements software (Nikon, Tokio, Japan); the analysis was done with ImageJ 1.42q software (NIH, MD, USA).

\section{$\mathrm{Ca}^{2+}$ signal}

The intracellular free-calcium signal (hereinafter termed the $\mathrm{Ca}^{2+}$ signal), was recorded as previously described (Harcha et al.,

TABLE 1 | Dye uptake of in HeLa-Cx39 cells via HCs.

\begin{tabular}{|c|c|c|c|c|}
\hline Commercial name & Molecular weight & Net charge & Dye uptake & Inhibited by HC blocker \\
\hline ACMA (9-Amino-6-Chloro-2-Methoxyacridine) & 258.7 & +1 & - & $\mathrm{n} / \mathrm{a}$ \\
\hline Methylene blue & 319.8 & +1 & + & + \\
\hline $\mathrm{DAPI}^{+2}$ & 350.2 & +2 & + & + \\
\hline Ethidium bromide & 394.3 & +1 & + & + \\
\hline Hexidium iodide & 497.4 & +1 & + & + \\
\hline Nuclear yellow & 651.0 & +1 & - & $\mathrm{n} / \mathrm{a}$ \\
\hline Propidium iodide & 668.3 & +2 & - & $\mathrm{n} / \mathrm{a}$ \\
\hline Procion Orange MX2R & 715.5 & -3 & + & + \\
\hline Indocyanine green & 774.9 & -1 & + & + \\
\hline $\mathrm{BBG}$ & 854.0 & -1 & - & $\mathrm{n} / \mathrm{a}$ \\
\hline Ethidium homodimer & 856.7 & +4 & - & $\mathrm{n} / \mathrm{a}$ \\
\hline Evans blue & 960.8 & -4 & + & + \\
\hline $\mathrm{BOBO}^{\mathrm{TM}}-1$ iodide & $1,202.6$ & +4 & - & $\mathrm{n} / \mathrm{a}$ \\
\hline 7-AAD (7-Aminoactinomycin D) & $1,270.4$ & 0 & + & + \\
\hline YOYO®-1 iodide & $1,270.7$ & +4 & + & + \\
\hline TOTO®-1 iodide & $1,302.8$ & +4 & + & + \\
\hline
\end{tabular}

n/a, Not applicable. 
2015). In brief, cells seeded on glass coverslips were loaded for $30 \mathrm{~min}$ at $37^{\circ} \mathrm{C}$ with $5 \mu \mathrm{M}$ Fura-2AM (Invitrogen, MA, USA) in the same saline solution used for the dye uptake assay, and were then washed with the same solution without Fura-2AM. For $\mathrm{Ca}^{2+}$ signal measurements, fluorescence intensity was captured every $3 \mathrm{~s}$. The fluorescence intensity ratio quantification $\left(\mathrm{Ca}^{2+}\right.$ signal $=$ F340/F380) and images were performed in a Nikon Eclipse Ti inverted microscope and imaged with NIS Elements software (Nikon, Tokio, Japan).

\section{Molecular Modeling}

Molecular models of both HCs and GJCs were produced using the human Cx26 (hCx26, PDB id: 2ZW3) crystal structure as a template (Maeda et al., 2009). Sequence alignments to produce molecular models were computed by introducing the amino acid sequence of the template, mouse $\mathrm{Cx} 39$ (mCx39) and mouse $\mathrm{Cx} 43$ $(\mathrm{mCx} 43)$ in the phylogenetic analysis previously proposed by Araya-Secchi et al. (Abascal and Zardoya, 2013; Araya-Secchi et al., 2014). To do so, multiple sequence alignments were recomputed by Mafft v7 (Araya-Secchi et al., 2012) using the PAM200 substitution matrix, and the slow strategy with an all-pair local alignment. Sequence identity versus the template structure resulted in $31.3 \%$ and $42.3 \%$ for $\mathrm{mCx} 39$ and $\mathrm{mCx} 43$, respectively. Spatial constraints needed to produce the molecular models of $\mathrm{mCx} 39$ and $\mathrm{mCx} 43$ were compiled from the template structure by using MODELLER v 9.14 (Eswar et al., 2006). In total, 1000 models were produced for each target sequence, whose structural quality was assessed by using MAIDEN (Postic et al., 2015). MAIDEN evaluates adjustments of the interatomic distance between residues located at transmembrane helices in the lipid bilayer using its empiric energy function. The top scored model for each protein was selected for further analysis.

\section{Pore Radius}

Pore radius profiles for our molecular models and the template crystal structure were computed with the Epock cavity detector plugin (Laurent et al., 2015), as implemented in VMD (Humphrey et al., 1996). To do so, a prospective axis of 120 and $200 \AA$ in length for HCs and GJCs, respectively, was traced along the $\mathrm{Z}$-axis of every molecular model. A scanning radius of $16 \AA$ was selected, where the available volume was computed by using a grid spacing of $0.5 \AA$.

\section{Assessment of the Electrostatic Potential}

The electrostatic potential of our molecular models was determined using PDB2PQR as implemented in the APBS 2.1 tool of PyMOL (Lerner and Carlson, 2006). This tool assigns hydrogen atoms and charges to molecular models according to the CHARMM forcefield. Then, the electrostatic potential was computed by using the Linearized Poisson-Boltzmann equation and default parameters. Figures were produced by using PyMOL's rendering capabilities.

\section{In silico Dye Modeling and Characterization}

All permeability probes were modeled using the Avogadro v1.0.3 suite (Hanwell et al., 2012). Molecular encoding was performed using the SMILES codes for each molecule obtained from NCBI's PubChem site (Bolton et al., 2008). When SMILES codes were not available, molecules were hand-drawn with Avogadro's drawing tool. All molecules were subjected to geometry optimization, performing an energy minimization procedure using the conjugate gradients algorithm and the MMFF94 forcefield (Halgren, 1996) within Avogadro. Next, a total of 1,875 molecular descriptors were calculated using the PaDEL-molecular descriptor program v2.21 (Yap, 2011). Descriptors that could not be computed for more than one molecule, or that were equal to 0 for all but one molecule, were discarded as non-informative. To select the descriptors that better represent the set of molecules, we used an approach based on K-nearest neighbors (KNN) classifiers combined with a genetic algorithm (GA) (Mitchell, 1996). Each GA-generated combination of descriptors was used to classify each molecule into two classes based on their ability to diffuse through mCx39 HCs. This classification was performed with a KNN classifier and a "leave-one-out" procedure. The GA employed works as follows: a population of 5,000 different subsets (i.e., genomes or solutions) of molecular descriptors was generated in the first iteration. Each of these genomes was a numerical vector of equal length to the total number of descriptors, in which the vector elements assigned to be used were set to 1 , whereas those descriptors not used were set to 0 . In the initial population, the first subset included all the descriptors that could be produced for all molecules (1,532 descriptors, all elements set to 1$)$. The next subsets were formed by each descriptor, and the remaining subsets were randomly chosen as a combination of descriptors. Subsequently, the top 1,000 subsets that correctly classified a larger number of molecules, passed directly (and unaltered) to the next generation, and were used to create the remaining 4,000 solutions. These 4,000 solutions were created by random cross-over of the top 1,000 subsets, followed by point mutations (a switch of the value in the vector element to the other possible value) that occurred with a probability of $10^{-3}$. During the cross-overs procedures, a vector position was randomly chosen to combine two of the top 1,000 genomes, creating 2 child genomes. This protocol ensures fast convergence to subsets of descriptors that were able to correctly classify all the molecules using the KNN.

\section{Statistical Analyses}

All results are presented as mean \pm SE and significant differences between groups were determined using a one-way ANOVA followed by a Tukey's multiple comparisons post-hoc test. Differences were considered significant at $P<0.05$. Statistical analyses were performed using Excel 2013 (Microsoft, WA, USA) and GraphPad Prism 6 software (Graphpad software, CA, USA).

\section{RESULTS AND DISCUSSION \\ HeLa-Cx39 Cells Do Not Form Functional Gap Junction Channels}

Cx43-EGFP fluorescence was intense at cell-cell contacts and more diffuse in perinuclear regions (Figure 1B right), consistent with functional cell-cell coupling (see below). In contrast, all 


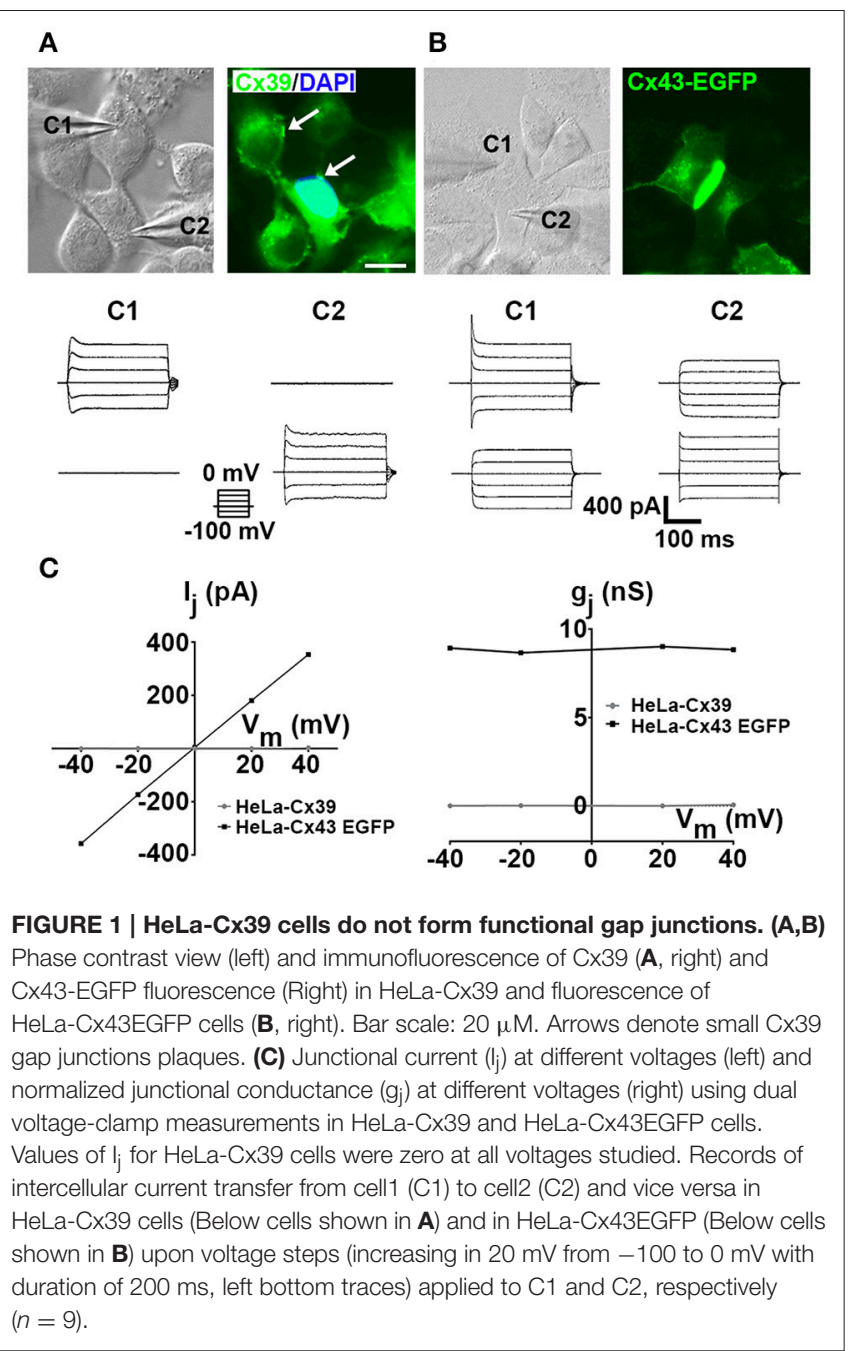

HeLa-Cx39 cells showed Cx39 reactivity mainly as diffused intracellular labeling as well as small patches in the cell periphery and at apparent cell-cell interfaces (Figure 1 A right, denoted by arrows), which does not rule out the possibility of functional gap junction formations. In addition, it remains to be confirm whether Cx39 from homotypic gap junctions using ultrastructure techniques, such immune-cryofracture or regular transmission electron microscopy. On the other hand, previous studies in HeLa-Cx39 cells have shown absence of dye transfer using Lucifer yellow, $\mathrm{DAPI}^{+2}$, propidium iodide, $\mathrm{Etd}^{+}$or neurobiotin (von Maltzahn et al., 2004). However, it remained unknown if cells expressing Cx39 can establish electrical coupling, which is a much more sensitive way of detecting gap junctional communication.

The application of $20 \mathrm{mV}$ voltage steps (from -100 to 0 $\mathrm{mV}$ with $200 \mathrm{~ms}$ duration) in HeLa-Cx43-EGFP cells generated evident transjunctional current $\left(\mathrm{I}_{\mathrm{j}}\right)$, which was not detected between HeLa-Cx39 cells $(n=9)$ (Figure 1C); values of $\mathrm{I}_{j}$ recorded in HeLa-Cx39 cells were zero at all voltages applied. Accordingly, and as previously described (von Maltzahn et al., 2004), intercellular DAPI $^{+2}$ transfer was negative (Figure 1A right). Calculation of junctional conductance $\left(g_{j}\right)$ from $I_{j}$ recorded at different membrane voltages in Cx43-EGFP yielded similar values within the voltage range illustrated $(-40 \mathrm{mV}$ to $+40 \mathrm{mV}$ ), indicating the absence of voltage dependence (Figure 1C). On the other hand, the $\mathrm{g}_{\mathrm{j}}$ between HeLa-Cx39 cells at any voltage applied was zero (Figure 1C), revealing the absence of ion flux between contacting HeLa-Cx39 cells.

Cxs that do not form GJCs are not without precedent, since mCx29 (Altevogt et al., 2002) and mCx33 (Chang et al., 1996) have been shown to convey no functional coupling in transfected mammalian cells or in Xenopus oocytes. However, positive dye coupling with Alexa488 has been observed in fresh preparations of diaphragm-striated muscle of neonatal mice, composed of myofibers that express only Cx39 (von Maltzahn et al., 2004). Since rhodamine dextran (10 kDa molecular mass) injected into a single myotube failed to spread into neighboring cells (von Maltzahn et al., 2004), the intercellular transfer of Alexa488 is likely to occur through a membrane channel with limited permeability properties. Nonetheless, dye coupling between fully differentiated mouse skeletal muscles has been blocked with suramine, implying the involvement of $\mathrm{P} 2$ receptors and perhaps the release and uptake of dye via HCs (Cea et al., 2013). Thus, it is yet to be explored whether a similar mechanism operates in diaphragm striated muscle of neonatal mice. If this is not the case, an alternative possibility could be that one or more factors/conditions for the formation of functional GJCs constituted by endogenously expressed Cx39 might be missing in HeLa cells. Hence, further studies might be necessary to fully rule out or demonstrate whether Cx39 forms GJCs in exogenous expression systems under conditions not studied in the present work (e.g., post-transcriptional modifications not expressed in HeLa cells). Moreover, the possible formation of functional heterotypic channels between homomeric Cx39 channels with other compatible $\mathrm{Cx}$ types also remains to be explored.

\section{Open Cx39 HCs Reduce Membrane Potential and Increase Total Membrane Current}

The low open probability of $\mathrm{Cx} 43 \mathrm{HCs}$ might explain the lack of influence on the RMP in HeLa-Cx43 cells (Contreras et al., 2003). To our knowledge similar studies have not been reported for HCs formed by other Cxs. Thus, as a first approach to study whether Cx39 HCs open under resting conditions, we explored whether they affect RMPs. The RMPs of HeLa Parental cells (HeLa-P cells) in control saline solution or DCFS were similar $(23.0 \pm 1.1 \mathrm{mV}$ V/S $21.6 \pm 1.5 \mathrm{mV}$, respectively, $n=20, p>0.05)$ (Figure 2A), consistent with the absence of $\mathrm{Cx}$ HCs. Accordingly, $\mathrm{La}^{3+}$, a HC blocker (Sáez et al., 2005; D’hondt et al., 2009), did not significantly affect the RMPs of HeLa-P cells $(-24.0 \pm$ $1.1 \mathrm{mV} \mathrm{V} / \mathrm{S}-23.0 \pm 1.1 \mathrm{mV}$, respectively, $n=20 p>0.05$ ) (Figure 2A). Moreover, the RMPs of HeLa-P cells were slightly higher than those of HeLa-Cx39 cells, but the differences were not statistically significant $(-23.1 \pm 1.1 \mathrm{mV}$ V/S $-19.7 \pm 1.7$ $\mathrm{mV}$, respectively, $n=20, p>0.05$ ) (Figure $2 \mathrm{~A}$ ), and the recorded values were similar to those previously measured in HeLa-P and HeLa-Cx43-EGFP cells (Contreras et al., 2003). In control saline solution the application of $200 \mu \mathrm{M} \mathrm{La}^{3+}$ significantly 


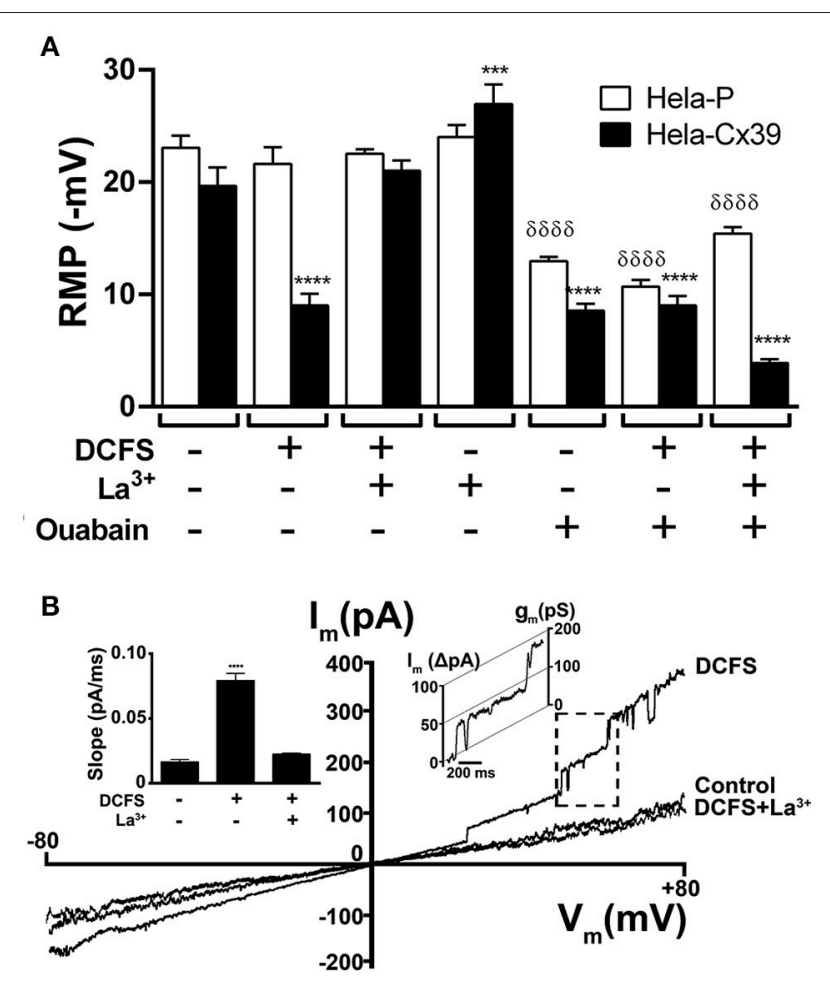

FIGURE 2 | DCFS reduces the resting membrane potential and increases the macroscopic membrane current of HeLa Cx39 cells. (A) The RMP of cells was measured using conventional microelectrodes. The graph shows the RMP of HeLa-P and HeLa-Cx39 cells bathed with normal saline solution or DCFS. In parallel experiments cells bathed with normal saline or DCFS were incubated for 30 min with $200 \mu \mathrm{M} \mathrm{La}{ }^{3+}$ or $100 \mathrm{nM}$ ouabain and the RMP was evaluated $\left({ }^{* * *} p<0.0001\right.$ and ${ }^{* * *} p<0.0005$ compared only between HeLa-Cx39 cells under control conditions v/s all conditions and ${ }^{\delta \delta \delta \delta} p<0.0001$ compared only between HeLa-P cells under control conditions $\mathrm{v} / \mathrm{s}$ all conditions) $n=40$ cells. (B) Representative membrane I/N curve obtained under application of a voltage ramp from -80 to $+80 \mathrm{mV}$ to HeLa-Cx39 cells under control conditions (Control) or DCFS or to DCFS-La ${ }^{3+}$ (200 $\mu \mathrm{M})$, a HCs blocker. The macroscopic current at $\mathrm{V}=0 \mathrm{mV}$ was zero in all conditions. Right inset shows a unitary current event (Rectangle of discontinuous lines) of approximately 75 pS, recorded in the membrane of a HeLa-Cx39 cell. Left inset shows the slope of macroscopic currents under different conditions $\left(n=10,{ }^{* \star * *} p<0.0001\right)$.

increased the RMPs of HeLa-Cx39 cells, compared with control conditions $(-27.0 \pm 1.8 \mathrm{mV} \mathrm{v} / \mathrm{s}-19.7 \pm 1.7 \mathrm{mV}$, respectively, $n$ $=20 p<0.005$ ), suggesting that inhibition of a few open Cx39 HCs significantly contributed to increasing the electrochemical gradient across the cell membrane. Moreover, the RMPs of HeLaCx39 cells bathed in DCFS were significantly lower compared with cells immersed with normal saline solution $(-9.0 \pm 1.1$ $\mathrm{mV}$ and $-19.7 \pm 1.7 \mathrm{mV}$, respectively, $n=20, p<0.0001)$, indicating that $\mathrm{Cx} 39 \mathrm{HCs}$ are inhibited by a divalent cation likely to be $\mathrm{Ca}^{2+}$, as demonstrated for other HCs (DeVries and Schwartz, 1992; Pfahnl and Dahl, 1999; Kondo et al., 2000; Contreras et al., 2003; Gómez-Hernández et al., 2003; Sáez et al., 2005; Lopez et al., 2014; Zonta et al., 2014). Upon exposure to DCFS containing $\mathrm{La}^{3+}(200 \mu \mathrm{M})$, the RMPs of HeLa-Cx39 cells bathed in DCFS were close to those recorded under control conditions $(-21.0 \pm 1.0 \mathrm{mV}$ v/s $-19.7 \pm 1.7 \mathrm{mV}$, respectively, $n=20 p>0.05$ ) (Figure 2A), suggesting that the inhibitory effect of $\mathrm{La}^{3+}$ predominates. Reductions in RMPs in HeLa-Cx39 cells exposed to DCFS are likely to be mediated by open Cx39 $\mathrm{HCs}$ that allow the transmembrane passage of ions (e.g., $\mathrm{Na}^{+}$ and $\left.\mathrm{K}^{+}\right)$. Accordingly, HCs formed by other Cxs have been shown to be permeable to $\mathrm{Na}^{+}$(Li et al., 2001) and $\mathrm{K}^{+}$(MiroCasas et al., 2009), and we found that $\mathrm{Cx} 39$ HCs are also nonselective channels. Thus, transmembrane $\mathrm{Na}^{+}$and $\mathrm{K}^{+}$gradients drive their diffusional movement, reducing the RMPs to new steady-state values. Although previous works have proposed a gating mechanism activated by $\mathrm{Ca}^{2+}$ (Gómez-Hernández et al., 2003; Lopez et al., 2014), recently a $\mathrm{Ca}^{2+}$ bound-Cx26 structure revealed that $\mathrm{Ca}^{2+}$ is coordinated at the M1/E1 boundary by residues from adjacent subunits, and was propose that $\mathrm{Ca}^{2+}$ binding functions as an electrostatic switch that dramatically reduces cation permeability (Bennett et al., 2016). Clearly, more studies are required to explain the mechanism of action of extracellular $\mathrm{Ca}^{2+}$ on $\mathrm{Cx}$ HCs but independent of this, we found a significant reduction in open probability of $\mathrm{Cx} 39 \mathrm{HCs}$ in $\mathrm{Ca}^{2+}$ containing extracellular solution (see below).

In most cells, the $\mathrm{Na}^{+} / \mathrm{K}^{+}$ATPase pump contributes to the maintenance of RMPs, and its inhibition causes depolarization (Redmann and Walliser, 1981). In agreement with the role of the $\mathrm{Na}^{+} / \mathrm{K}^{+}$ATPase on the RMP, 30 min treatment in control saline solution or in DCFS with ouabain $(0.1 \mu \mathrm{M})$, which is a $\mathrm{Na}^{+} / \mathrm{K}^{+}$ATPase pump inhibitor (Clausen et al., 1983), significantly reduced RMPs to a similar extent in HeLa-Cx39 cells $(-8.5 \pm 0.6 \mathrm{mV}$ and $-9.0 \pm 1.1 \mathrm{mV}$, respectively $\mathrm{V} / \mathrm{S}-19.7$ $\pm 1.7 \mathrm{mV}$ in control saline solution, $n=20 p<0.0001)$ and HeLa-P cells $(-10.7 \pm 0.6 \mathrm{mV}$ and $-13.0 \pm 0.4 \mathrm{mV}$, respectively $\mathrm{V} / \mathrm{S}-23.0 \pm 1.1 \mathrm{mV} n=20 p<0.0001$ ) (Figure 2A). In addition, Cx39 HC opening in DCFS together with ouabain caused a similar fall in RMPs to that caused by each treatment alone (Figure 2A), suggesting that intrinsic features of the cells prevent a complete drop in RMPs. A possible cause might be the presence of intracellular non-diffusible and non-transportable charged molecules and/or the presence of other compensatory ion transporters. Surprisingly, treatment with $\mathrm{La}^{3+}$ plus ouabain caused a further reduction in RMP as compared to treatment ouabain alone, which we cannot explained and requires future studies

To further test that DCFS increases the open probability of Cx39 HCs, we measured the macroscopic and microscopic membrane current of HeLa-Cx39 cells using the whole-cell voltage clamp configuration. The membrane current recorded (Figure 2B) and the current slope calculated from curve current v/s time (Figure 2B, left inset) under control conditions was low and similar to that of HeLa-P cells (not illustrated) $(0.016$ $\pm 0.008 \mathrm{pA} / \mathrm{mS} \mathrm{V} / \mathrm{S} 0.013 \pm 0.005 \mathrm{pA} / \mathrm{ms}$, respectively $p>$ $0.05 n=10$ ). However, the membrane current of HeLa-Cx39 cells significantly increased upon exposure to extracellular DCFS, particularly at positive membrane potentials $(>+25 \mathrm{mV})$ and drastically decreased upon $200 \mu \mathrm{M} \mathrm{La}^{3+}$ treatment $(0.080 \pm$ $0.006 \mathrm{pA} / \mathrm{ms} \mathrm{V} / \mathrm{S} 0.020 \pm 0.001 \mathrm{pA} / \mathrm{ms}$, respectively, $n=5$ $p<0.0001)$. It should be noted that the $\mathrm{I} / \mathrm{V}$ curve recorded in the presence of extracellular divalent cations (control conditions) 
was comparable to that recorded in DCFS plus $\mathrm{La}^{3+}$ (Figure 2B), suggesting that most, if not all, the increase in membrane current induced by DCFS was due to Cx39 HC opening. The increase in macroscopic currents induced by DCFS was reverted by $\mathrm{La}^{3+}$ at basal macroscopic current level in all conditions, at $0 \mathrm{mV}, \mathrm{I}=0$, indicating that $\mathrm{Cx} 39 \mathrm{HCs}$ have no ionic selectivity like $\mathrm{Cx} 43 \mathrm{HCs}$ (Kondo et al., 2000; Contreras et al., 2003).

Upon application of voltage ramps, the membrane current curves showed unitary events that were frequently observed at positive potentials in HeLa-Cx39 cells exposed to DCFS (Figure 2B). Values of discrete current transitions were pointby-point converted to conductance values, revealing values of unitary events of $\sim 75 \mathrm{pS}$ (Figure 2B, inset in the right panel of the graph). In DCFS, the open probability of unitary current events increased with respect to control conditions, and indicated that the most frequent unitary events was $75 \pm 5 \mathrm{pS}$. The opening and closure transition times of $\mathrm{Cx} 39 \mathrm{HCs}$ were slower than those of Cx43-EGFP HCs in DCFS, but Cx39 HCs had the same open and closure times (Figure 2B, left inset). Similar values of transition times have been observed previously in $\mathrm{Cx} 43$ HCs (Contreras et al., 2003) and Cx56-HCs (Ebihara et al., 1999). In HeLa-P cells the application of DCFS did not induce the appearance of discrete unitary current events, as previously reported (Contreras et al., 2003; Retamal et al., 2007; Sánchez et al., 2009).

The unitary current events were also evaluated using rectangular voltage steps. HeLa-P cells held at $+60 \mathrm{mV}$ in either control saline solution or DCFS did not elicit unitary current events (Figure 3A). Similar results were obtained in HeLa-P cells transfected with the empty vector (not illustrated). In contrast, in HeLa-Cx39 cells unitary events with a rather low open probability $\left(P_{\mathrm{o}}=0.3\right)$ were evident after holding the membrane voltage at $+60 \mathrm{mV}$ for about $20 \mathrm{~s}$. However, in cells exposed to DCFS, discrete unitary current events showed a higher open probability $\left(P_{\mathrm{o}}=0.9\right)$, and were completely blocked by $200 \mu \mathrm{M}$ $\mathrm{La}^{3+}$ (Figure 3A). The most frequent discrete event recorded in HeLa-Cx39 cells presented unitary events values of $\sim 75 \pm 5 \mathrm{pS}$ $(n=40)$ either in control or DCFS solution (Figures $\mathbf{3 A}, \mathbf{B})$. The transition times from the full-closed to full-open states, and viceversa, of Cx39 HCs were not significantly different $(21.0 \pm 0.5$ $\mathrm{ms} \mathrm{v} / \mathrm{s} 20.4 \pm 0.5 \mathrm{~ms}, P>0.05, n=30$ ) (Figure 3C), but both values were lower than those of Cx43-EGFP HCs (full-closed to full-open: $27.2 \pm 1.9 \mathrm{~ms} \mathrm{v} / \mathrm{s} 32.6 \pm 2.8 \mathrm{~ms}, P<0.05, n=30$ and full-open to full-closed: $20.4 \pm 0.5 \mathrm{~ms}$ v/s $32.6 \pm 2.8 \mathrm{~ms}, P<$ $0.0001, n=30$ ) (Figure 3C).

\section{Cx39 HCs Enable the Passage of a Selective Group of Molecules with Different Physicochemical Properties}

Different dyes (e.g., $\mathrm{DAPI}^{+2}, \mathrm{Etd}^{+}$and propidium) have been used before to observe changes in membrane permeability due to the presence of Cx HCs (Orellana et al., 2011; Hansen et al., 2014). However, the selectivity of the $\mathrm{Cx}$ pores is not easily visualized with a short list of permeability probes. To identify permeability features of Cx39 HCs, we performed real-time dye uptake experiments using molecules with different molecular masses and

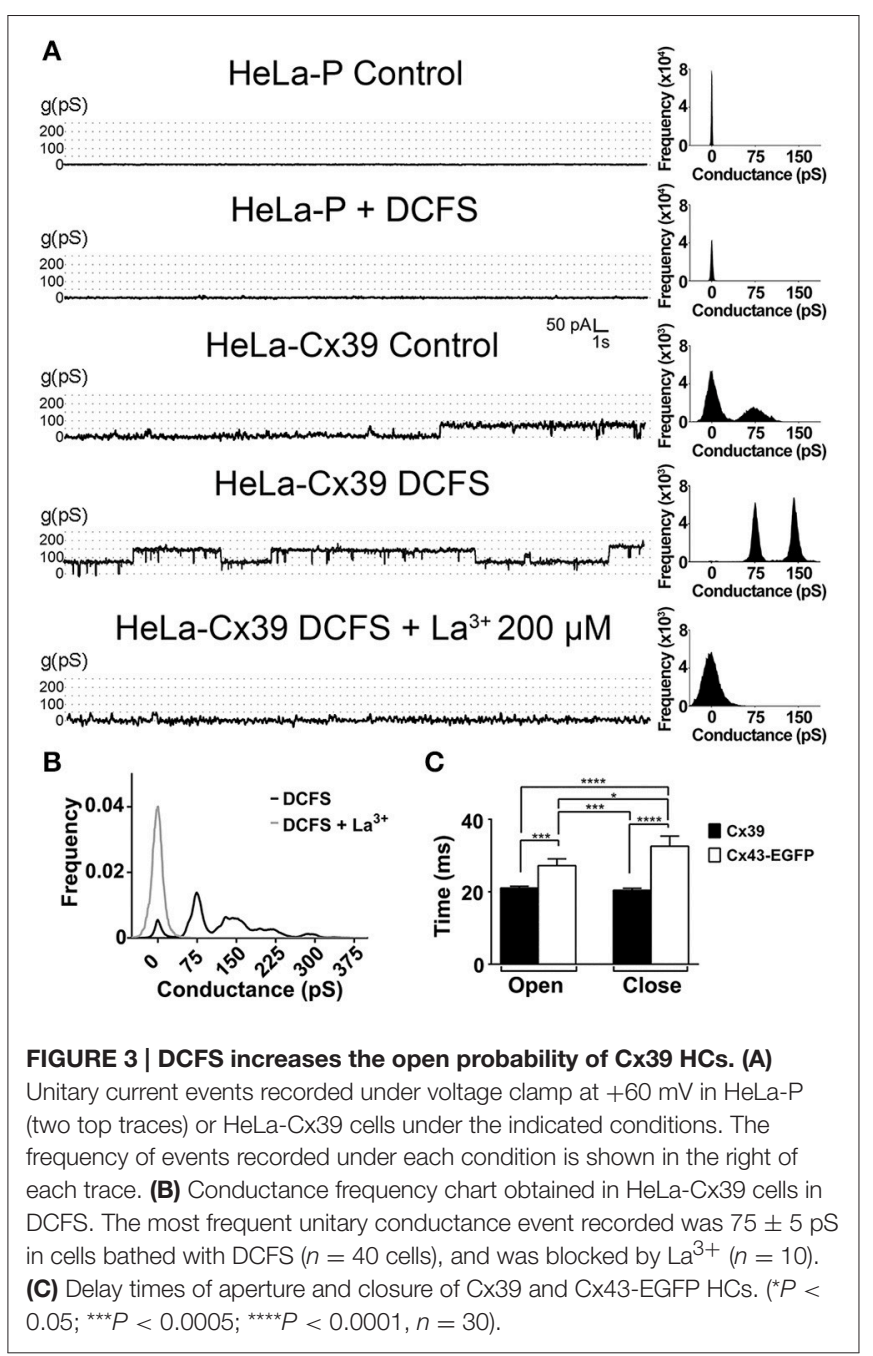

net charges that fluoresce upon binding to intracellular nucleic acids and proteins (Table 1 and Figure 4).

HeLa-P cells did not show changes in ethidium uptake upon exposure to DCFS (Figure 4, inset). Similarly HeLaCx39 cells in the presence of extracellular divalent cations showed very low uptake of ethidium $(+1)$ and propidium $(+2)$. After exposing HeLaCx39 cells to DCFS, only ethidium uptake increased drastically and was completely blocked by $200 \mu \mathrm{M}$ $\mathrm{La}^{3+}$ (Figure 4, inset). In fact, the uptake rate of all dyes used in HeLa-Cx39 cells was very low under control conditions, but the uptake rate of several dyes increased significantly upon exposure to DCFS; $\mathrm{Etd}^{+}$, DAPI $(+2)$, Evans blue $(-4)$, hexidium iodide $(+1)$, methylene blue $(+1)$ and procion orange $\operatorname{MX} 2 \mathrm{R}(-3)$, and was canceled out by $\mathrm{La}^{3+}$ (Figure 4). In contrast, the uptake rate of propidium $(+)$ showed a tendency to increase in DCFS that was reduced by $\mathrm{La}^{3+}$ (not statistically significant), whereas the uptake rate of ethidium homodimer $(+4)$ and BBG $(-1)$ was not significantly affected either by DCFS or $\mathrm{La}^{3+}$ (Figure 4). In agreement with the lack of HCs, the dye uptake rate of HeLa-P cells was almost zero in either control saline solution or after exposure to DCFS alone or with $\mathrm{La}^{3+}$ (not shown). 
The permeability of $\mathrm{Cx} 39 \mathrm{HCs}$ to molecules varied between large molecules with high net charge, like TOTO (MW: 1,300, +4), YOYO (MW: 1,200, +4) or Evans blue (MW:

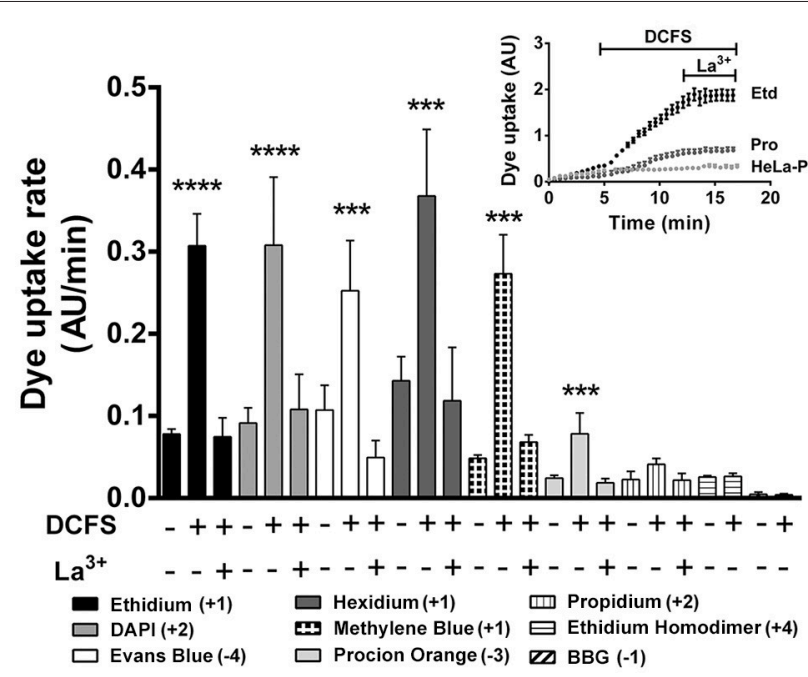

FIGURE 4 | The dye uptake of HeLa-Cx39 cells is increased by DCFS. Uptake rate of the different molecules with different molecular mass and net charge (Bottom list) of HeLa-Cx39 cells under each condition indicated ( $n=6$ for each dye). Inset shows representative real time ethidium ( $\mathrm{Etd}^{+}$) and propidium (Pro) uptake, HeLa-Cx39 cells respectively, and Etd ${ }^{+}$in HeLa-P. After 5 min recording under control conditions, the extracellular solution was quickly changed by DCFS and dye uptake was recorded for 8 min followed by additional 5 min recording in the presence of $200 \mu \mathrm{M} \mathrm{La}^{3+} .\left(^{\star \star \star \star} P<0.0001\right.$ and ${ }^{* \star *} p<0.0005$ compared to basal value in each case; $n=4$, with 30 cells recorded in each case). $\mathrm{AU}$, arbitrary Units.
$960,-4)$, to smaller molecules with lower net charges, which are not able to pass through HCs-Cx39, such as ACMA dye (MW: $258,+1)$ or with high net charge, such as ethidium homodimer (MW: $857,+4)$. Because permeable dyes differ in terms of their molecular nature (Table 1), explaining why a dye can pass through Cx39 HCs depends on considering the nature of the $\mathrm{Cx} 39 \mathrm{HC}$ and the molecular features of the dyes. Since the above findings suggest a lack of correlation between size and charge, we decided to use a machine-learning approach to analyze the molecular features of permeant molecules in order to further understand the permeability properties of $\mathrm{Cx} 39 \mathrm{HCs}$ (see below).

\section{Electronegativity, Ionization Potential, Flexibility, Valence, Size, Polarizability and Geometry Are Key Features of Small Molecules to Define Their Passage through mCx39 HCs}

Determining permeability features with various dyes could provide useful information about the physical and chemical nature of the pores and their affinity to certain molecules, according to their net charge, size or shape. However, these selection criteria appear to be insufficient to identify the basic features of molecules that cross the cell membrane through Cx39 HCs (see above). To overcome this limitation, we used a machine-learning approach to explore the physicochemical properties of the different permeability probes tested in the present work. We identified 11 out of 1,000 molecular descriptors (Table 2) that correctly classified the dyes in terms of their ability to permeate mCx39 HCs (Table 1). Among the selected physicochemical properties, the most frequent belong to six

TABLE 2 | Raw data of the selected molecular descriptors for each tested molecule.

\begin{tabular}{|c|c|c|c|c|c|c|c|c|c|c|}
\hline Category B3:L14 & Descriptor & $\begin{array}{l}\text { Ethidium } \\
\text { bromide }\end{array}$ & $\mathrm{DAPI}^{+2}$ & $\begin{array}{l}\text { Evans } \\
\text { blue }\end{array}$ & $\begin{array}{l}\text { Hexidium } \\
\text { iodide }\end{array}$ & $\begin{array}{l}\text { Methylene } \\
\text { blue }\end{array}$ & $\begin{array}{c}\text { Procion } \\
\text { orange } \\
\text { MX2R }\end{array}$ & $\begin{array}{l}\text { Propidium } \\
\text { iodide }\end{array}$ & $\begin{array}{c}\text { Ethidium } \\
\text { homodimer-2 }\end{array}$ & BBG \\
\hline \multirow[t]{3}{*}{ Electronegativity } & TDB6e & 41.75 & 45.31 & 53.62 & 42.18 & 45.98 & 51.98 & 41.28 & 41.16 & 40.90 \\
\hline & ATSC5s & -0.13 & 1.50 & -311.14 & 2.62 & 1.91 & -37.82 & 9.71 & 15.42 & 6.61 \\
\hline & GATS5s & 0.67 & 0.77 & 1.25 & 0.66 & 0.77 & 1.07 & 0.57 & 0.56 & 0.54 \\
\hline \multirow[t]{2}{*}{ Ionization potential } & TDB8i & $1,254.65$ & $1,362.00$ & $1,201.18$ & $1,188.58$ & $1,312.73$ & $1,188.57$ & $1,171.03$ & $1,179.16$ & $1,103.96$ \\
\hline & TDB10i & $1,816.65$ & $1,733.37$ & $1,460.62$ & $1,515.93$ & $1,773.06$ & $1,451.99$ & $1,402.39$ & $1,418.41$ & $1,296.55$ \\
\hline Polarizability & TDB6p & 8.32 & 8.26 & 8.61 & 8.51 & 9.33 & 10.12 & 7.71 & 7.96 & 7.87 \\
\hline \multirow[t]{3}{*}{ Size and geometry } & TDB6r & 1.82 & 1.87 & 2.29 & 1.85 & 2.00 & 2.49 & 1.71 & 1.76 & 1.71 \\
\hline & TDB6v & $1,080.21$ & $1,100.05$ & 1,333.31 & $1,114.43$ & $1,121.27$ & $1,460.71$ & $1,005.28$ & $1,039.38$ & $1,018.14$ \\
\hline & TDB5u & 4.91 & 4.90 & 4.99 & 4.94 & 4.87 & 5.04 & 4.68 & 4.76 & 4.80 \\
\hline Topological flexibility & RotBtFrac & 0.19 & 0.22 & 0.30 & 0.29 & 0.23 & 0.27 & 0.35 & 0.32 & 0.34 \\
\hline Valence & VP-6 & 2.15 & 1.04 & 2.57 & 2.72 & 1.82 & 1.95 & 3.15 & 6.92 & 3.36 \\
\hline
\end{tabular}

\ All values of permeable molecules are higher than values of impermeant ones.

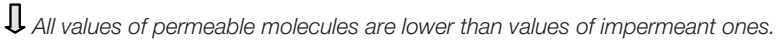


different categories: (1) electronegativity, (2) ionization potential, (3) polarizability, (4) size and geometry, (5) flexibility and (6) valence. While the values of some molecular descriptor were higher (TDB6e, ATSC5s, GATS5s, TDB8i, TDB10i, TDB6v, and TDB5u) those of others were smaller (RotBtFrac and VP-6) for permeant molecules as compared to non-permeant molecules (Table 1). All other descriptors did not follow this pattern and, thus, were not included in Table 2 (Table S1). An extended explanation for each descriptor can be reviewed in the Supplementary Materials and Methods section. Since some values of several descriptors are common features to all permeant molecules, while others are characteristic of non-permeant molecules, the value of one descriptor alone is not enough to establish whether a particular molecule is permeant or not. Therefore, the permeability of dyes could be understood as an emergent property obtained from a non-linear combination of several physicochemical properties: electronegativity, ionization potential, flexibility, valence, size, polarizability and geometry. Despite non-linearity, still some relationships between these properties could be obtained. As electronegativity is proportional to valence, it is expected that descriptors TDB6e, ATSC5s, GATS5s and VP-6 would show similar trends (i.e., electronegative patches are spread and separated, and low valence atoms are close to each other). Procion orange MX2R and Evans blue have many $\mathrm{SO}_{3}^{-}$groups distributed throughout their structure, and permeate through $\mathrm{mCx} 39 \mathrm{HCs}$. $\mathrm{BBG}$ also has a couple of $\mathrm{SO}_{3}^{-}$groups, but as discussed below, size-related descriptors hint as to why it does not permeate. Ionization potentials (8i/10i) and polarizability (TDB6p) also show similar trends, mainly due to the fact that most tested dyes have resonance structures that allow electron delocalization (i.e., polarizability spread throughout the molecule). In the case of propidium, although it has similar resonance structures like ethidium and hexidium, it possesses two positive charges close to each other. This is the contrary to what happens for $\mathrm{DAPI}^{+2}$, since its two positive charges are far from each other. Interestingly, molecular flexibility tends to be inversely related to dye diffusion through Cx39 HCs: dyes with lowest uptake rates (Propidium, ethidium homodimer and BBG) have the highest values for the RotBtFrac descriptors (Table 2). This notion is reinforced because, on a visual inspection, BBG and the ethidium homodimer present bulkier structures than the rest of the molecules (as suggested by descriptors TDB6r, TDB6v, and TDB5u), although they have similar molecular weights and van der Waals volumes to Evans blue (data not shown). Moreover, $\mathrm{DAPI}^{+2}$, Evans blue and methylene blue have an overall linear structure, while $\mathrm{Etd}^{+}$and hexidium iodide are relatively small, which might favor their diffusion through Cx39 HCs. In the case of procion orange MX2R, although being a negatively charged molecule such as Evans blue, it possesses two chloride atoms that may make its diffusion difficult. Pore radius may also be a factor impeding these bulky molecules from diffusing freely through mCx39 HCs. In contrast to other Cx HCs, mCx39 HC exhibits a constriction at the $\mathrm{PH}$ region that is absent in $\mathrm{hCx} 26 \mathrm{HC}$ and $\mathrm{mCx} 43 \mathrm{HC}$. Hence, it is evident that bulkier structures, such as BBG and the ethidium homodimer, will have more difficulty crossing the barrier formed by the $\mathrm{PH}$ region of $\mathrm{mCx} 39$. As for propidium, although its structure is similar to ethidium and hexidium, it possesses a quaternary ammonium group, which can rotate freely, changing the radius of gyration of the molecule and possibly hindering its diffusion through Cx39 HCs.

\section{Open Cx39 HCs Do Not Enable $\mathrm{Ca}^{2+}$ Influx}

To evaluate $\mathrm{Ca}^{2+}$ uptake, it is necessary to use a stimulus that opens $\mathrm{Cx}$ HCs in the presence of extracellular $\mathrm{Ca}^{2+}$, as it occurs upon exposure to alkaline $\mathrm{pH}$ (Schalper et al., 2010). Thus, we

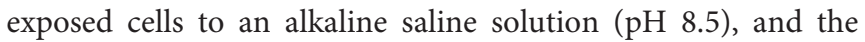
$\mathrm{Etd}^{+}$uptake and $\mathrm{Ca}^{2+}$ signals were simultaneously evaluated. As previously demonstrated, HeLa-Cx43 cells showed an increase in $\mathrm{Etd}^{+}$uptake as well as in $\mathrm{Ca}^{2+}$ signal (Figures 5A,B). The same treatment induced $\mathrm{Etd}^{+}$uptake in HeLa-Cx39 cells $(9.3 \pm 1.3$ $\mathrm{AU} / \mathrm{min} \mathrm{v} / \mathrm{s} 2.4 \pm 0.4 \mathrm{AU} / \mathrm{min}$, respectively $p<0.0001 n=4$ ) (Figure 5A), but $\mathrm{Ca}^{2+}$ signal was not significantly modified (Figure 5B, inset). On the other hand, HeLa-P cells exposed to alkaline $\mathrm{pH}$ did not show changes in $\mathrm{Etd}^{+}$uptake and $\mathrm{Ca}^{2+}$ signal (Figures 5A,B).

To further study the possible permeability of Cx39 HCs to $\mathrm{Ca}^{2+}$, we induced $\mathrm{HC}$ opening by applying mechanical stress,

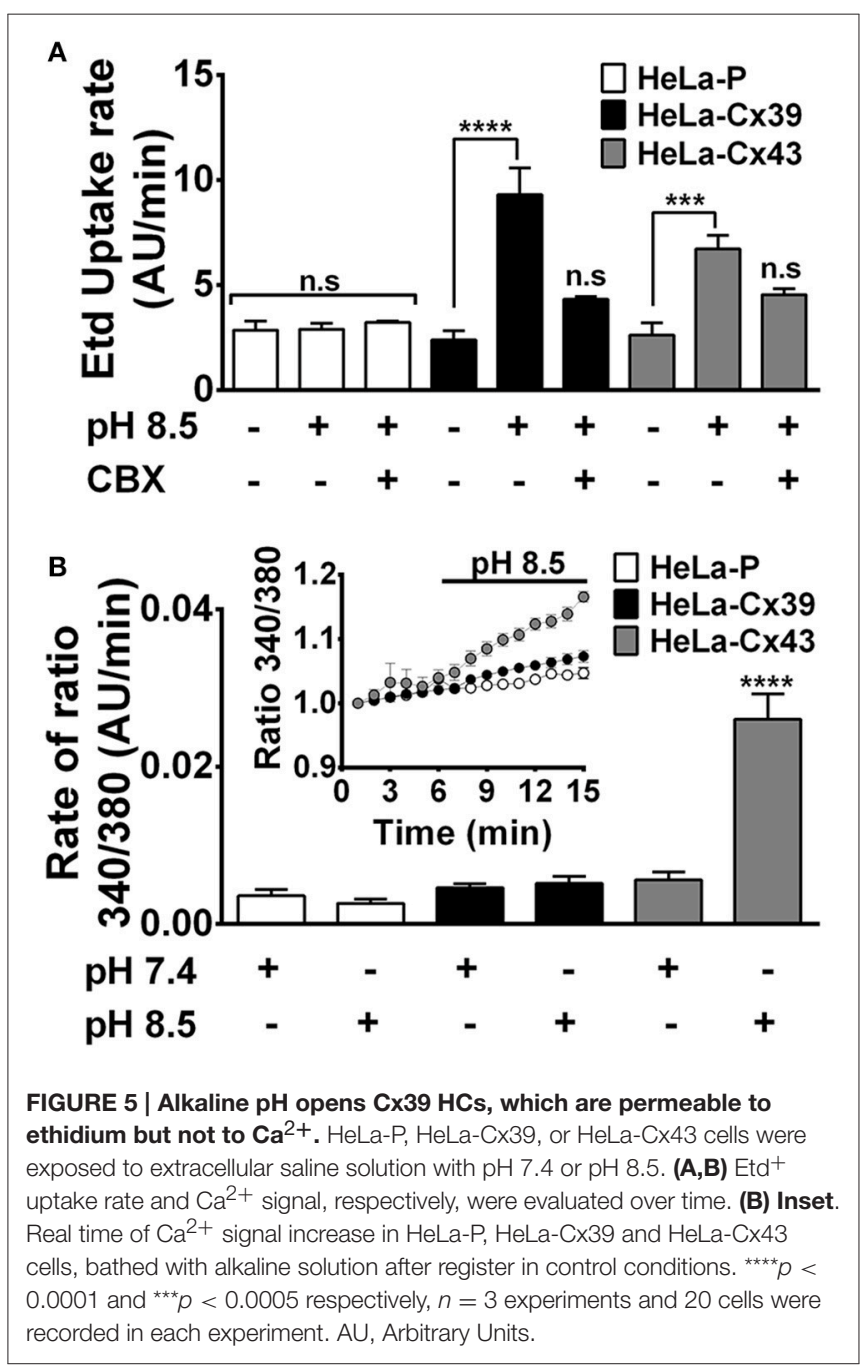


a stimulus that induces opening of HCs constituted of other Cxs and in other cell types (Stout et al., 2002; Batra et al., 2012). We found a direct relationship between the intensity of mechanical stress and the rate of $\mathrm{Etd}^{+}$uptake in HeLa-Cx39 cells (Figure 6A). While the application of 2 serial stimuli of 1 $\mathrm{ml}$ from $15 \mathrm{~cm}$ high did not significantly increase dye uptake rate, the application of 4 stimuli caused similar increases in dye uptake rate as those induced by 6 or 8 stimuli (Figure 6A). These increases in dye uptake were completely suppressed by $\mathrm{La}^{3+}$ applied during the time-lapse measurement (Figure 6A), indicating that the dye uptake occurred through Cx39 HCs. It should be noted that applying 8 stimuli to HeLa-P cells did not increase dye uptake (Figure 6A), which is consistent with the absence of Cx39 HCs. Then, we evaluated possible $\mathrm{Ca}^{2+}$ influx in HeLa-Cx39 cells, and found no increase in intracellular $\mathrm{Ca}^{2+}$ signal after mechanical stimulation (Figure 6B). However, the application of the $2.5 \mu \mathrm{M}$ calcium ionophore A23187 rapidly increased the $\mathrm{Ca}^{2+}$ signal that afterwards decreased progressively (Figure 6B), possibly due to the increase in open probability of $\mathrm{Cx} 39 \mathrm{HCs}$ by the increase in intracellular $\mathrm{Ca}^{2+}$ induced by

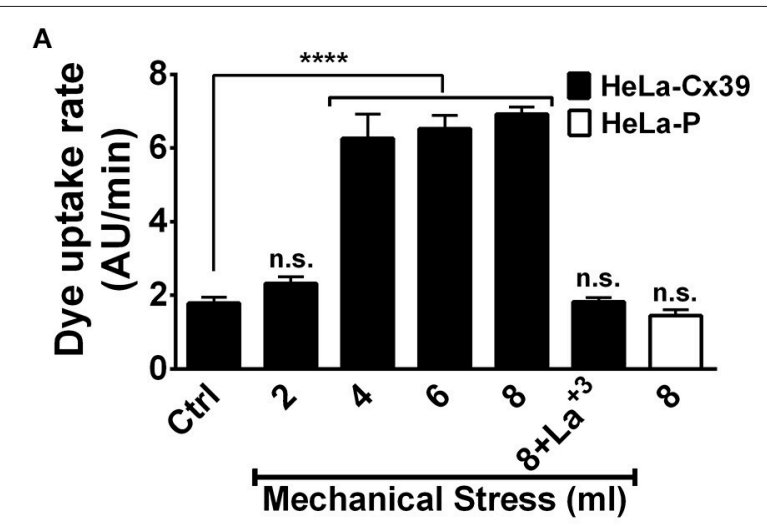

B

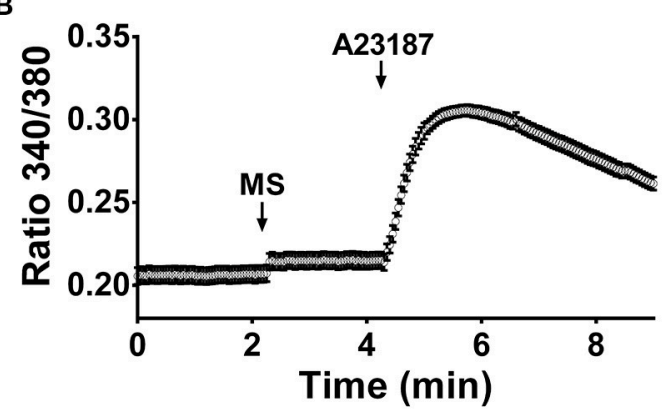

FIGURE 6 | Cx39 HCs of cells exposed to mechanical stress are permeable to ethidium but not to $\mathbf{C a}^{2+}$. (A) Dye $\left(\mathrm{Etd}^{+}\right)$uptake rate of HeLa-P and HeLa-Cx39 cells mechanical stimulated with different volumes of saline solution from $15 \mathrm{~cm}$ high under control conditions. HeLa-Cx39 cells were also mechanically stimulated with $8 \mathrm{ml}$ in the presence of $200 \mu \mathrm{M} \mathrm{La}^{3+}$ $\left(8+\mathrm{La}^{3+}\right)$. HeLa-P cells were also stimulated with $8 \mathrm{ml}$ of saline solution. $\left(^{\star \star \star \star} \mathrm{p}\right.$ $<0.0001, n=5$ with 30 cells recorder in each case). (B) Intracellular $\mathrm{Ca}^{2+}$ signal of HeLa-Cx39 cells under control conditions (first $2.5 \mathrm{~min}$ ), after mechanical stimulation ( $8 \mathrm{ml}$ from $15 \mathrm{~cm}$ high) and after the addition of $2.5 \mu \mathrm{M}$ of 4-Bromo calcium ionophore A23187 to increase calcium in the cells. MS, mechanical stress. the ionophore as observed for other Cx HCs (De Vuyst et al., 2006, 2009), which could favor the leakage of Fura-2 to the extracellular solution. Interestingly Cx39 HCs are the first $\mathrm{HC}$ shown to be impermeable to $\mathrm{Ca}^{2+}$, suggesting that is opening might less harmful for cells under pathological conditions such in denervation skeletal muscle (Cea et al., 2013) and in Duchenne muscular dystrophy (Cea et al., 2016)

\section{Dye Uptake of Hela-Cx39 Cells Is Sensitive to Some, But Not All, HC Blockers}

Several GJ and HC blockers have been described and their properties have been reviewed (Hervé and Sarrouilhe, 2005; Bodendiek and Raman, 2010; Verselis and Srinivas, 2013). Although Cx39 HCs (Figures 2B, 4 inset) and $\mathrm{Cx} 43 \mathrm{HCs}$ (Contreras et al., 2003) are rapidly blocked by $\mathrm{La}^{3+}$ in cells exposed to DCFS, the application of $310 \mu \mathrm{M}$ octanol, $350 \mu \mathrm{M}$ heptanol, $50 \mu \mathrm{M} \beta$-glycyrrhetinic acid, $100 \mu \mathrm{M}$ oleamide and 50 $\mu \mathrm{M}$ carbenoxolone did not block after inducing $\mathrm{HC}$ opening by DCFS. This suggests that these agents do not block open Cx39 or Cx43 HCs. However, co-application of $50 \mu \mathrm{M} \beta$-glycyrrhetinic acid, $100 \mu \mathrm{M}$ oleamide or $50 \mu \mathrm{M}$ carbenoxolone with DCFS to HeLa-Cx39 and Cx43 HeLa-EGFP cells significantly precluded the dye uptake increase induced by DCFS in both HeLa-Cx43 and -Cx39 cells, suggesting that they block Cx39 HCs in the closed state. In contrast, heptanol and octanol did not prevent DCFSinduced dye uptake in HeLa-Cx39 cells (Figure 7). Nevertheless,

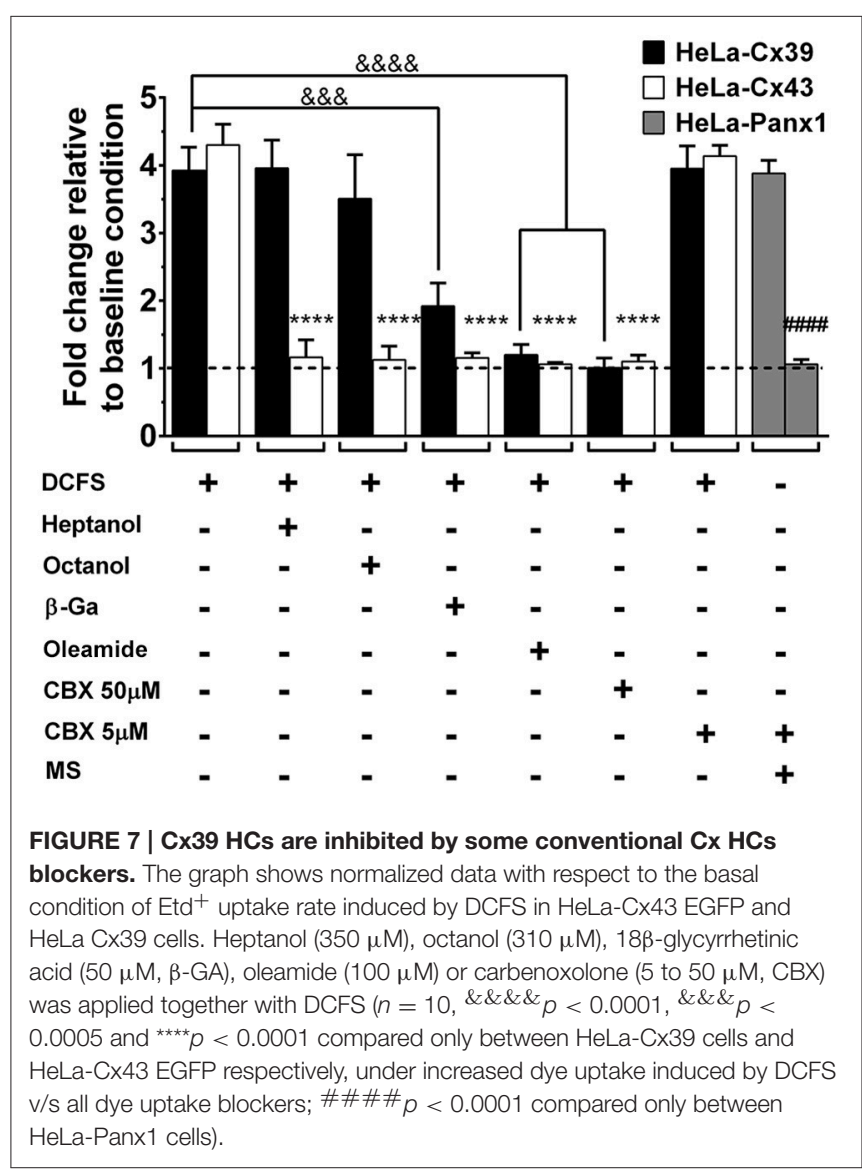


these two alcohols effectively prevented the DCFS-induced opening of $\mathrm{Cx} 43 \mathrm{HCs}$ (Figure 7). The action of long-chain alcohols like heptanol has been explained by their effects on membrane fluidity (Bastiaanse et al., 1993), while a specific and high-affinity interaction with $\mathrm{Cx} 50 \mathrm{HCs}$ has been reported for octanol (Eskandari et al., 2002) the lack of such a high-affinity domain in $\mathrm{Cx} 39 \mathrm{HC}$ might explain the insensitivity of this $\mathrm{HC}$ to heptanol and octanol.
A

\section{$\mathrm{hCx} 26$ \\ $\mathrm{mCx} 39$

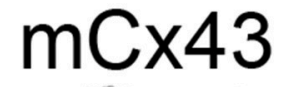

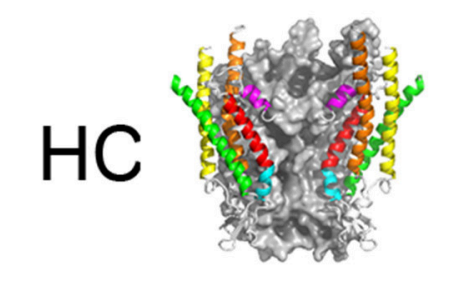
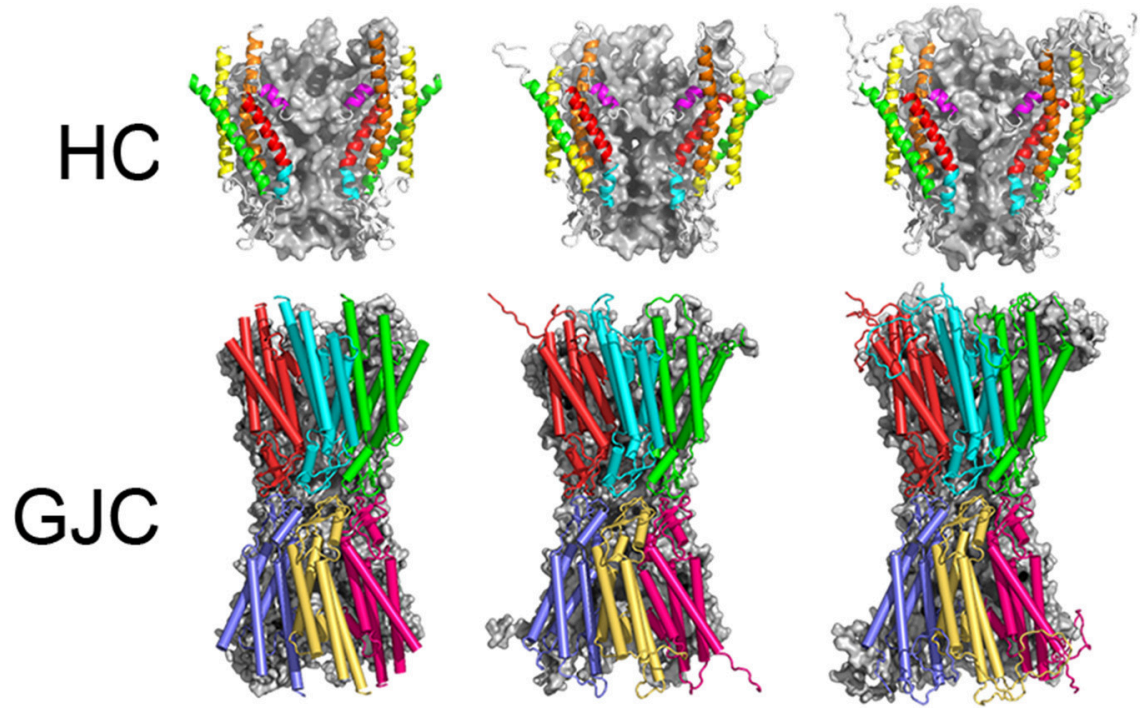

B
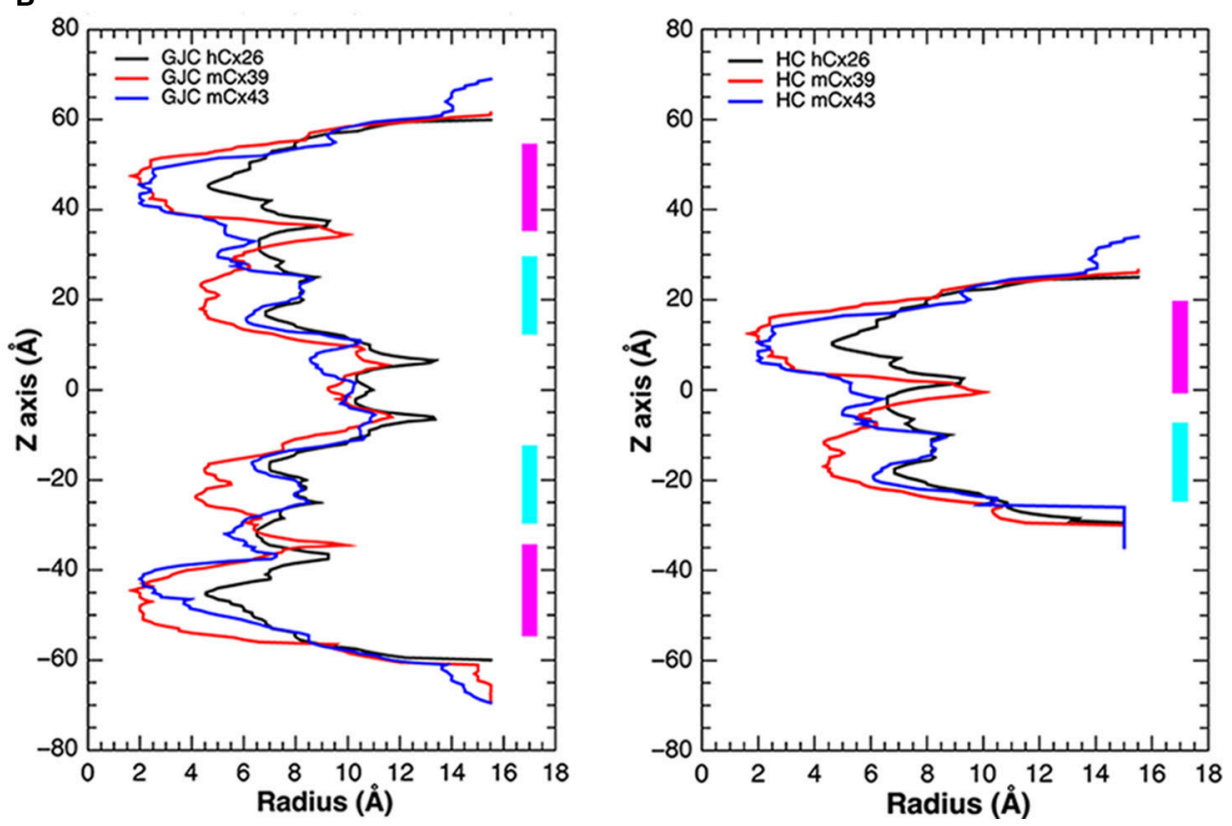

FIGURE 8 | mCx39 resemble a Cx based channel but exhibit structural differences in PH region compared with mCx43 an hCx26. (A) Top row, structural representations of the $\mathrm{hC} \times 26$ crystal structure of the $\mathrm{HC}$ used as a template, and the molecular models of $\mathrm{mCx} 39$ and mCx43. Each $\mathrm{HC}$ shows two monomers that are depicted by ribbons and color coded to represent different regions of the protein (NTH = magenta, $\mathrm{TM} 1=\mathrm{red}, \mathrm{PH}=\mathrm{Cyan}, \mathrm{TM} 2=\mathrm{orange}, \mathrm{TM} 3=\mathrm{yellow}$, and TM4 = green). Two other monomers are depicted in a gray solid surface, while the other two at the front were omitted for clarity. (A) Bottom row, structural representations of the hCx26 GJC used as template, and the molecular models of $\mathrm{mCx} 39$ and mCx43. Each $\mathrm{HC}$ shows three monomers that are depicted by cartoons (cylinders $=$ alpha helices, arrows $=$ beta sheets, tubes $=$ coils and loops) and color coded to differentiate from each other. (B) Pore radius along the $z$-axis of the $\mathrm{Cx}$ channels. Left, pore radius along the z-axis calculated for the hCx26 crystal structure (black) of the GJCs and the mCx39 (red) and Cx43 (blue) molecular model. Right, pore radius along the z-axis calculated for the hCx26 crystal structure (black) of the HC and the mCx39 (red) and Cx43 (blue) molecular models. The $\mathrm{NTH}$ region is depicted in magenta while the $\mathrm{PH}$ regions appears in cyan. 
The structurally related classical $\mathrm{Cx} \mathrm{HC}$ blockers, $\beta$-glycyrrhetinic acid and carbenoxolone, partially and completely blocked the activity of Cx39 HCs (Figure 7). These derivatives seem to affect many different GJCs without being specific to any $\mathrm{Cx}$ subtype, and the proposed mechanism of action would involve the insertion of glycyrrhetinic derivatives into the plasma membrane, hence binding to the GJC subunits at hydrophobic sites and inducing a conformational change that leads to channel closure (Davidson et al., 1986).

Since carbenoxolone $(50 \mu \mathrm{M})$ is known to block $\mathrm{Cx}$ and Panx1 HCs (Bruzzone et al., 2005), which are rather insensitive to heptanol (Pelegrin and Surprenant, 2006), the possibility that Cx39 HCs present pharmacological sensitivity similar to Panx1 HCs was also studied. To this end, we tested whether a low carbenoxolone concentration (5 $\mu \mathrm{M} \mathrm{CBX})$, which is a classical Panx1 HC blocker (Bruzzone et al., 2005; Ma et al., 2009), affects the functional state of Cx39 HCs. Opening of Panx1 HCs was induced with mechanical stress in HeLa-Panx1 cells used as controls (Bao et al., 2004; Locovei et al., 2006; Taylor et al., 2015), and $5 \mu \mathrm{M}$ CBX drastically reduced the dye uptake. In contrast, 5 $\mu \mathrm{M}$ CBX did not affect the mechanical stress-induced dye uptake in HeLa-Cx39 cells (Figure 7).

\section{Molecular Modeling of Cx39 and Cx43 HCs}

To gain insight into the structural and/or functional differences between $\mathrm{mCx} 39$ and $\mathrm{mCx} 43$, which may help us explain why the former are not able to produce functional GJCs in Hela cells, we developed a set of molecular models for both HCs and GJCs based on the hCx26 crystal structure as a template (Figure 8A). As expected and independent of individual sequence variations, all models resemble the general structure of the $\mathrm{hCx} 26$ channel. However, some differences in the pore structure along the channel can be found (Figure 8A, top row). To determine if these structural differences may influence channel function, the pore radius for all HCs and GJCs was computed (see Materials and Methods). The pore radius of hCx26 in both GJCs (Figure 8B left) and HCs (Figure 8B right) shows the narrowest constriction at the N-terminal helix (NTH) region, which reaches $4.5 \AA$, while the widest part is found at the extracellular side of the Para-Helix (PH) region, with a pore radius near $14 \AA$. The pore radius calculated for $\mathrm{mCx} 39$ - and $\mathrm{mCx} 43$-based channels follows a similar tendency, showing the narrowest part of the pore at the NTH region, reaching a radius less than $2 \AA$. Both channels exhibit the widest part of their pore at the extracellular side of the $\mathrm{PH}$ region, similar to hCx26-based channels, reaching a radius near to $12 \AA$. Of note, the pore radius of $\mathrm{mCx} 39$ in GJCs (Figure 8B left) and HCs (Figure 8B right) exhibits a notorious constriction, which is absent in the other structures: a pore radius near $4 \AA$ at the intracellular side of the $\mathrm{PH}$ region.

According to the authors of the crystal structure of $\mathrm{hCx} 26$, this channel was obtained in its open state (Maeda et al., 2009). However, molecular dynamics (MD) simulations performed by Kwon et al. (2011) using the crystal structure of the hCx26 HC concluded that this structure is unlikely to represent an open channel. Moreover, later on, Zonta et al. (2013) reached the same conclusion: the $\mathrm{hCx} 26$ crystal structure should be in its closed conformation. Despite this controversy, available experimental evidence suggest that the NTH region is related to voltagedependent fast-gating of the channel (Oh and Bargiello, 2015). Therefore, we hypothesized that any restriction present in this region could be affected by the relocalization of the NTH in the presence of a transmembrane potential difference. This notion is supported by previous work that suggests that the voltage sensor can be an integral part of the NTH (Ek-Vitorin and Burt, 2013; Araya-Secchi et al., 2014).

On the other hand, $\mathrm{mCx} 39$ exhibits a singular constriction at the intracellular side of the $\mathrm{PH}$ region that is absent in the $\mathrm{mCx} 43$ and hCx26 template structure. Similar to NTH, this region has also been related to voltage-dependent gating of Cx-based channels, namely the slow gating (Oh and Bargiello, 2015). As mentioned before, HeLa cells expressing Cx39 do not form functional GJCs. Therefore, we hypothesize that the constriction present in $\mathrm{mCx} 39$ at the $\mathrm{PH}$ region could respond to a transmembrane voltage difference. If this is the case, apart from the apparent steric restriction, the $\mathrm{PH}$ region should also present other features that may explain lack of GJC functionality.

Interestingly, the recent release of a hCx 26 crystal structure obtained in the presence of extracellular $\mathrm{Ca}^{2+}$, suggest that despite both regions the $\mathrm{NTH}$ and the $\mathrm{PH}$ could respond to voltage differences across the cellular membrane, the $\mathrm{Ca}^{2+}$ induced channel blockage could be the result of an electrostatic blockage instead of a set of conformational changes (Bennett et al., 2016).

To further explore the implications of these structural differences between $\mathrm{mCx} 39$ and $\mathrm{mCx} 43$, considering their sequence variation, we decided to compute the electrostatic potential of our molecular models. The electrostatic potential of both $\mathrm{hCx} 26$ and $\mathrm{mCx} 43$, exhibits a general trend. The

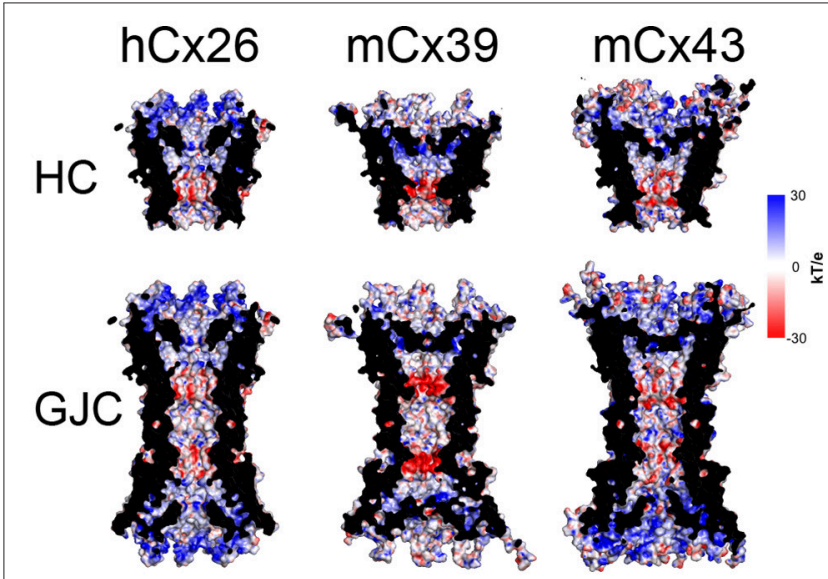

FIGURE 9 | Molecular surface along the pore of Cx-based channels colored by electrostatic potential. Top row, the electrostatic potential mapped onto the molecular surface of the hCx26 crystal structure of the $\mathrm{HC}$ used as a template, and the $\mathrm{mCx} 39$ and $\mathrm{mCx} 43$ molecular models. Bottom row, the electrostatic potential mapped onto the molecular surface of the hCx26 crystal structure of the GJC used as a template, and the mCx39 and mCx43 molecular models. All structural representations depict 4 monomers per $\mathrm{HC}$ while the other two at the front were omitted for clarity. Color coding corresponds to the value of the electrostatic potential according to the spectrum shown at the right (in kT/e units). 
intracellular portion shows an electropositive confluence, whereas the extracellular side tends to be electronegative, showing a diffuse pattern in which negative charges are mixed primarily with neutral regions and, to a lesser extent, with positive regions (Figure 9). Interestingly, $\mathrm{mCx} 39$ escapes this trend by exhibiting a more neutral intracellular side, showing a diffuse pattern of positive charges, and a markedly electronegative confluence at the extracellular side flanked by two neutral regions located at both sides of this negative charge accumulation (Figure 9). Moreover, this electronegative patch co-localizes with the unique constriction exhibited by mCx39 at the intracellular region of the $\mathrm{PH}$ (Figure 9). Considering the importance of the localization of charges for the ionic selectivity of Cx-based channels (Ek-Vitorin and Burt, 2013; Escalona et al., 2016) it is expected that any alteration to this pattern could hinder ion currents or voltage sensing, hence affecting channel function. A possible functional consequence of the homotypic docking could be cell-cell addition, which is an important Cx function frequently overlooked

\section{CONCLUSIONS}

Results reported here demonstrate that $\mathrm{Cx} 39$ forms functional HCs with distinct unitary conductance $(75 \pm 5 \mathrm{pS})$ and inhibited by extracellular $\mathrm{Ca}^{2+}$, however it does not form functional GJCs. Cx39 $\mathrm{HCs}$ are preferentially permeable to molecules characterized by six categories of descriptors, namely (1) electronegativity, (2) ionization potential, (3) polarizability, (4) size and geometry, (5) topological flexibility and (6) valence. Unlike other Cx HCs, Cx39 HCs are not permeable to $\mathrm{Ca}^{2+}$ and show different in sensitivity to classical HC and GJC blockers.

\section{REFERENCES}

Abascal, F., and Zardoya, R. (2013). Evolutionary analyses of gap junction protein families. Biochim. Biophys. Acta 1828, 4-14. doi: 10.1016/j.bbamem.2012.02.007

Altevogt, B. M., Kleopa, K. A., Postma, F. R., Scherer, S. S., and Paul, D. L. (2002). Connexin29 is uniquely distributed within myelinating glial cells of the central and peripheral nervous systems. J. Neurosci. 22, 6458-6470.

Araya-Secchi, R., Lagos, C. F., Abarca, F., Martinez, A. D., and PerezAcle, T. (2012). Molecular dynamics simulations of Cx26-Wt and deafness related mutants M34A, A40G and V37I. Biophys. J. 102, 106a-107a. doi: 10.1016/j.bpj.2011.11.600

Araya-Secchi, R., Perez-Acle, T., Kang, S. G., Huynh, T., Bernardin, A., Escalona, Y., et al. (2014). Characterization of a novel water pocket inside the human Cx26 hemichannel structure. Biophys. J. 107, 599-612. doi: 10.1016/j.bpj.2014.05.037

Bao, L., Locovei, S., and Dahl, G. (2004). Pannexin membrane channels are mechanosensitive conduits for ATP. FEBS Lett. 572, 65-68. doi: 10.1016/j.febslet.2004.07.009

Bao, X., Lee, S. C., Reuss, L., and Altenberg, G. A. (2007). Change in permeant size selectivity by phosphorylation of connexin 43 gap-junctional hemichannels by PKC. Proc. Natl. Acad. Sci. U.S.A. 104, 4919-4924. doi: $10.1073 /$ pnas.0603154104

\section{AUTHOR CONTRIBUTIONS}

BAC performed permeability experiments, FS performed electrophysiological experiments, $\mathrm{CU}$ and LAC performed permeability experiments, AHV designed and performed electrophysiological experiments. SEGM, AJMM analyzed bioinformatics data of dyes and wrote the paper, CPB, YE performed in silico model and wrote the paper, TPA designed bioinformatics experiments and wrote the paper, OS and CFL wrote the paper, and AAV designed and performed electrophysiological and permeability experiments and wrote the paper and JCS designed research and wrote the paper.

\section{ACKNOWLEDGMENTS}

We thank to Ms. Teresa Vergara and Ms. Paola Fernández for their technical support. This work was partially supported by Fondo Nacional de Desarrollo Científico y Tecnológico (FONDECYT) grants 1150291 (to JCS), 11140342 (to AJMM), 11160739 (to LAC) and 1160574 (to TPA), Fundación Ciencia para la Vida PFB-16 (to TPA), and ICM-Economía P09-022-F Centro Interdisciplinario de Neurociencias de Valparaíso (to JCS and TPA), PAI/CONICYT 79140023 (to LAC) and the Doctoral thesis support fellowship at CONICYT to AAV and SEGM. The data of this paper are from a thesis submitted in partial fulfillment of the requirements for the degree of Doctor in Physiological Sciences (AAV) at the Pontificia Universidad Católica de Chile.

\section{SUPPLEMENTARY MATERIAL}

The Supplementary Material for this article can be found online at: http://journal.frontiersin.org/article/10.3389/fphys. 2017.00038/full\#supplementary-material

Bastiaanse, E. M., Jongsma, H. J., van der Laarse, A., and Takens-Kwak, B. R. (1993). Heptanol-induced decrease in cardiac gap junctional conductance is mediated by a decrease in the fluidity of membranous cholesterol-rich domains. J. Membr. Biol. 136, 135-145.

Batra, N., Burra, S., Siller-Jackson, A. J., Gu, S., Xia, X., Weber, G. F., et al. (2012). Mechanical stress-activated integrin alpha5betal induces opening of connexin 43 hemichannels. Proc. Natl. Acad. Sci. U.S.A. 109, 3359-3364. doi: 10.1073/pnas.1115967109

Beahm, D. L., and Hall, J. E. (2002). Hemichannel and junctional properties of connexin 50. Biophys. J. 82, 2016-2031. doi: 10.1016/S0006-3495(02) 75550-1

Bennett, B. C., Purdy, M. D., Baker, K. A., Acharya, C., McIntire, W. E., Stevens, R. C., et al. (2016). An electrostatic mechanism for $\mathrm{Ca}(2+)$-mediated regulation of gap junction channels. Nat. Commun. 7, 8770. doi: 10.1038/ncomms 9770

Bennett, M. V., Contreras, J. E., Bukauskas, F. F., and Sàez, J. C. (2003). New roles for astrocytes: gap junction hemichannels have something to communicate. Trends Neurosci. 26, 610-617. doi: 10.1016/j.tins.2003.09.008

Bodendiek, S. B., and Raman, G. (2010). Connexin modulators and their potential targets under the magnifying glass. Curr. Med. Chem. 17, 4191-4230. doi: 10.2174/092986710793348563

Bolton, E. E., Wang, Y., Thiessen, P. A., and Bryant, S. H. (2008). "PubChem: integrated platform of small molecules and biological activities," in Annual Reports in Computational Chemistry, eds A. W. Ralph and C. S. David (Amsterdam: Elsevier), 217-241. 
Bruzzone, R., Barbe, M. T., Jakob, N. J., and Monyer, H. (2005). Pharmacological properties of homomeric and heteromeric pannexin hemichannels expressed in Xenopus oocytes. J. Neurochem. 92, 1033-1043. doi: 10.1111/j.1471-4159.2004.02947.x

Cea, L. A., Cisterna, B. A., Puebla, C., Frank, M., Figueroa, X. F., Cardozo, C., et al. (2013). De novo expression of connexin hemichannels in denervated fast skeletal muscles leads to atrophy. Proc. Natl. Acad. Sci. U.S.A. 110, 16229-16234. doi: 10.1073/pnas.1312331110

Cea, L. A., Puebla, C., Cisterna, B. A., Escamilla, R., Vargas, A. A., Frank, M., et al. (2016). Fast skeletal myofibers of mdx mouse, model of Duchenne muscular dystrophy, express connexin hemichannels that lead to apoptosis. Cell. Mol. Life Sci. 73, 2583-2599. doi: 10.1007/s00018-016-2132-2

Chang, M., Werner, R., and Dahl, G. (1996). A role for an inhibitory connexin in testis? Dev. Biol. 175, 50-56. doi: 10.1006/dbio.1996.0094

Clausen, T., Kjeldsen, K., and Nørgaard, A. (1983). Effects of denervation on sodium, potassium and $[3 \mathrm{H}]$ ouabain binding in muscles of normal and potassium-depleted rats. J. Physiol. 345, 123-134.

Contreras, J. E., Sáez, J. C., Bukauskas, F. F., and Bennett, M. V. (2003). Gating and regulation of connexin $43(\mathrm{Cx} 43)$ hemichannels. Proc. Natl. Acad. Sci. U.S.A. 100, 11388-11393. doi: 10.1073/pnas.1434298100

Contreras, J. E., Sánchez, H. A., Eugenin, E. A., Speidel, D., Theis, M., Willecke, K., et al. (2002). Metabolic inhibition induces opening of unapposed connexin 43 gap junction hemichannels and reduces gap junctional communication in cortical astrocytes in culture. Proc. Natl. Acad. Sci. U.S.A. 99, 495-500. doi: 10.1073/pnas.012589799

Davidson, J. S., Baumgarten, I. M., and Harley, E. H. (1986). Reversible inhibition of intercellular junctional communication by glycyrrhetinic acid. Biochem. Biophys. Res. Commun. 134, 29-36.

DeVries, S. H., and Schwartz, E. A. (1992). Hemi-gap-junction channels in solitary horizontal cells of the catfish retina. J. Physiol. 445, 201-230.

De Vuyst, E., Decrock, E., Cabooter, L., Dubyak, G. R., Naus, C. C., Evans, W. H., et al. (2006). Intracellular calcium changes trigger connexin 32 hemichannel opening. EMBO J. 25, 34-44. doi: 10.1038/sj.emboj.7600908

De Vuyst, E., Wang, N., Decrock, E., De Bock, M., Vinken, M., Van Moorhem, M., et al. (2009). $\mathrm{Ca}(2+)$ regulation of connexin 43 hemichannels in C6 glioma and glial cells. Cell Calc. 46, 176-187. doi: 10.1016/j.ceca.2009.07.002

D'hondt, C., Iyyathurai, J., Vinken, M., Rogiers, V., Leybaert, L., Himpens, B., et al. (2013). Regulation of connexin- and pannexin-based channels by post-translational modifications. Biol. Cell 105, 373-398. doi: 10.1111/boc.201200096

D’ondt, C., Ponsaerts, R., De Smedt, H., Bultynck, G., and Himpens, B. (2009). Pannexins, distant relatives of the connexin family with specific cellular functions? Bioessays 31, 953-974. doi: 10.1002/bies.200800236

Ebihara, L., Xu, X., Oberti, C., Beyer, E. C., and Berthoud, V. M. (1999). Co-expression of lens fiber connexins modifies hemi-gap-junctional channel behavior. Biophys. J. 76(1 Pt 1), 198-206. doi: 10.1016/S0006-3495(99)77189-4

Ek-Vitorin, J. F., and Burt, J. M. (2013). Structural basis for the selective permeability of channels made of communicating junction proteins. Biochim. Biophys. Acta 1828, 51-68. doi: 10.1016/j.bbamem.2012.02.003

Escalona, Y., Garate, J. A., Araya-Secchi, R., Huynh, T., Zhou, R., and PerezAcle, T. (2016). Exploring the membrane potential of simple dual-membrane systems as models for gap-junction channels. Biophys. J. 110, 2678-2688. doi: 10.1016/j.bpj.2016.05.005

Eskandari, S., Zampighi, G. A., Leung, D. W., Wright, E. M., and Loo, D. D. (2002). Inhibition of gap junction hemichannels by chloride channel blockers. J. Membr. Biol. 185, 93-102. doi: 10.1007/s00232-0010115-0

Eswar, N., Webb, B., Marti-Renom, M. A., Madhusudhan, M. S., Eramian, D., Shen, M. Y., et al. (2006). Comparative protein structure modeling using Modeller. Curr. Protoc. Bioinf. Chapter 5, Unit 5. 6. doi: 10.1002/0471250953.bi0506s15

Figueroa, V. A., Retamal, M. A., Cea, L. A., Salas, J. D., Vargas, A. A., Verdugo, C. A., et al. (2014). Extracellular gentamicin reduces the activity of connexin hemichannels and interferes with purinergic $\mathrm{Ca}(2+)$ signaling in HeLa cells. Front. Cell. Neurosci. 8:265. doi: 10.3389/fncel.2014.00265

Figueroa, X. F., Lillo, M. A., Gaete, P. S., Riquelme, M. A., and Sáez, J. C. (2013). Diffusion of nitric oxide across cell membranes of the vascular wall requires specific connexin-based channels. Neuropharmacology 75, 471-478. doi: 10.1016/j.neuropharm.2013.02.022
Gómez-Hernández, J. M., de Miguel, M., Larrosa, B., González, D., and Barrio, L. C. (2003). Molecular basis of calcium regulation in connexin-32 hemichannels. Proc. Natl. Acad. Sci. U.S.A. 100, 16030-16035. doi: 10.1073/pnas.2530348100.

Halgren, T. A. (1996). Merck molecular force field. I. Basis, form, scope, parameterization, and performance of MMFF94. J. Comput. Chem. 17, 490-519. doi: 10.1002/(SICI)1096-987X(199604)17:5/6<490::AID-JCC1>3.0. CO;2-P

Hansen, D. B., Braunstein, T. H., Nielsen, M. S., and MacAulay, N. (2014). Distinct permeation profiles of the connexin 30 and 43 hemichannels. FEBS Lett. 588, 1446-1457. doi: 10.1016/j.febslet.2014.01.036

Hanwell, M. D., Curtis, D. E., Lonie, D. C., Vandermeersch, T., Zurek, E., and Hutchison, G. R. (2012). Avogadro: an advanced semantic chemical editor, visualization, and analysis platform. J. Cheminform. 4:17. doi: 10.1186/1758-2946-4-17

Harcha, P. A., Vargas, A., Yi, C., Koulakoff, A. A., Giaume, C., and Sáez, J. C. (2015). Hemichannels are required for amyloid beta-peptide-induced degranulation and are activated in brain mast cells of APPswe/PS1dE9 Mice. J. Neurosci. 35, 9526-9538. doi: 10.1523/JNEUROSCI.3686-14.2015

Harris, A. L. (2001). Emerging issues of connexin channels: biophysics fills the gap. Q. Rev. Biophys. 34, 325-472. doi: 10.1017/S0033583501003705

Hervé, J. C., and Sarrouilhe, D. (2005). Connexin-made channels as pharmacological targets. Curr. Pharm. Des. 11, 1941-1958. doi: $10.2174 / 1381612054021060$

Humphrey, W., Dalke, A., and Schulten, K. (1996). VMD: visual molecular dynamics. J. Mol. Graph 14, 33-38, 27-38.

Jordan, K., Solan, J. L., Dominguez, M., Sia, M., Hand, A., Lampe, P. D., et al. (1999). Trafficking, assembly, and function of a connexin43-green fluorescent protein chimera in live mammalian cells. Mol. Biol. Cell 10, 2033-2050.

Koehler Leman, J., Ulmschneider, M. B., and Gray, J. J. (2015). Computational modeling of membrane proteins. Proteins 83, 1-24. doi: 10.1002/prot.24703

Kondo, R. P., Wang, S. Y., John, S. A., Weiss, J. N., and Goldhaber, J. I. (2000). Metabolic inhibition activates a non-selective current through connexin hemichannels in isolated ventricular myocytes. J. Mol. Cell. Cardiol. 32, 1859-1872. doi: 10.1006/jmcc.2000.1220

Kwon, T., Harris, A. L., Rossi, A., and Bargiello, T. A. (2011). Molecular dynamics simulations of the Cx26 hemichannel: evaluation of structural models with Brownian dynamics. J. Gen. Physiol. 138, 475-493. doi: 10.1085/jgp.2011 10679

Laurent, B., Chavent, M., Cragnolini, T., Dahl, A. C., Pasquali, S., Derreumaux, P., et al. (2015). Epock: rapid analysis of protein pocket dynamics. Bioinformatics 31, 1478-1480. doi: 10.1093/bioinformatics/btu822

Lerner, M., and Carlson, H. (2006). APBS Plugin for PyMOL. Ann Arbor: University of Michigan.

Li, F., Sugishita, K., Su, Z., Ueda, I., and Barry, W. H. (2001). Activation of connexin-43 hemichannels can elevate $[\mathrm{Ca}(2+)] \mathrm{i}$ and $[\mathrm{Na}(+)] \mathrm{i}$ in rabbit ventricular myocytes during metabolic inhibition. J. Mol. Cell. Cardiol. 33, 2145-2155. doi: 10.1006/jmcc.2001.1477

Locovei, S., Bao, L., and Dahl, G. (2006). Pannexin 1 in erythrocytes: function without a gap. Proc. Natl. Acad. Sci. U.S.A. 103, 7655-7659. doi: 10.1073/pnas.0601037103

Lopez, W., Liu, Y., Harris, A. L., and Contreras, J. E. (2014). Divalent regulation and intersubunit interactions of human connexin26 (Cx26) hemichannels. Channels 8, 1-4. doi: 10.4161/chan.26789

Ma, W., Hui, H., Pelegrin, P., and Surprenant, A. (2009). Pharmacological characterization of pannexin-1 currents expressed in mammalian cells. J. Pharmacol. Exp. Ther. 328, 409-418. doi: 10.1124/jpet.108. 146365

Maeda, S., Nakagawa, S., Suga, M., Yamashita, E., Oshima, A., Fujiyoshi, Y., et al. (2009). Structure of the connexin 26 gap junction channel at $3.5 \mathrm{~A}$ resolution. Nature 458, 597-602. doi: 10.1038/nature07869

Miro-Casas, E., Ruiz-Meana, M., Agullo, E., Stahlhofen, S., Rodríguez-Sinovas, A., Cabestrero, A., et al. (2009). Connexin43 in cardiomyocyte mitochondria contributes to mitochondrial potassium uptake. Cardiovasc. Res. 83, 747-756. doi: $10.1093 / \mathrm{cvr} / \mathrm{cvp} 157$

Mitchell, M. (1996). An Introduction to Genetic Algorithms. Massachusetts: Bradford Books.

Oh, S., and Bargiello, T. A. (2015). Voltage regulation of connexin channel conductance. Yonsei Med. J. 56, 1-15. doi: 10.3349/ymj.2015.56.1.1 
Oh, S., Rivkin, S., Tang, Q., Verselis, V. K., and Bargiello, T. A. (2004). Determinants of gating polarity of a connexin 32 hemichannel. Biophys. J. 87, 912-928. doi: 10.1529/biophys.103.038448

Orellana, J. A., Díaz, E., Schalper, K. A., Vargas, A. A., Bennett, M. V., and Sáez, J. C. (2011). Cation permeation through connexin 43 hemichannels is cooperative, competitive and saturable with parameters depending on the permeant species. Biochem. Biophys. Res. Commun. 409, 603-609. doi: 10.1016/j.bbrc.2011.05.031

Orellana, J. A., and Stehberg, J. (2014). Hemichannels: new roles in astroglial function. Front. Physiol. 5:193. doi: 10.3389/fphys.2014.00193

Pelegrin, P., and Surprenant, A. (2006). Pannexin-1 mediates large pore formation and interleukin-1beta release by the ATP-gated P2X7 receptor. EMBO J. 25, 5071-5082. doi: 10.1038/sj.emboj.7601378

Pfahnl, A., and Dahl, G. (1999). Gating of cx46 gap junction hemichannels by calcium and voltage. Pflugers Arch. 437, 345-353. doi: 10.1007/s004240050788

Postic, G., Ghouzam, Y., and Gelly, J. C. (2015). An empirical energy function for structural assessment of protein transmembrane domains. Biochimie 115, 155-161. doi: 10.1016/j.biochi.2015.05.018

Puebla, C., Cisterna, B. A., Salas, D. P., Delgado-López, F., Lampe, P. D., and Sáez, J. C. (2016). Linoleic acid permeabilizes gastric epithelial cells by increasing connexin 43 levels in the cell membrane via a GPR40and Akt-dependent mechanism. Biochim. Biophys. Acta. 1861, 439-448. doi: 10.1016/j.bbalip.2016.02.002

Redmann, K., and Walliser, S. (1981). Different changes in transmembrane potential of cultured cells after ouabain-inhibited active $\mathrm{Na}+/ \mathrm{K}+$-transport. Arch. Geschwulstforsch. 51, 96-102.

Retamal, M. A., Cortés, C. J., Reuss, L., Bennett, M. V., and Sáez, J. C. (2006). Snitrosylation and permeation through connexin 43 hemichannels in astrocytes: induction by oxidant stress and reversal by reducing agents. Proc. Natl. Acad. Sci. U.S.A. 103, 4475-4480. doi: 10.1073/pnas.0511118103

Retamal, M. A., Schalper, K. A., Shoji, K. F., Bennett, M. V., and Sáez, J. C. (2007). Opening of connexin 43 hemichannels is increased by lowering intracellular redox potential. Proc. Natl. Acad. Sci. U.S.A. 104, 8322-8327. doi: 10.1073/pnas.0702456104

Sáez, J. C., Berthoud, V. M., Branes, M. C., Martinez, A. D., and Beyer, E. C. (2003). Plasma membrane channels formed by connexins: their regulation and functions. Physiol. Rev. 83, 1359-1400. doi: 10.1152/physrev.00007.2003

Sáez, J. C., Retamal, M. A., Basilio, D., Bukauskas, F. F., and Bennett, M. V. (2005). Connexin-based gap junction hemichannels: gating mechanisms. Biochim. Biophys. Acta 1711, 215-224. doi: 10.1016/j.bbamem.2005.01.014

Sánchez, H. A., Orellana, J. A., Verselis, V. K., and Sáez, J. C. (2009). Metabolic inhibition increases activity of connexin-32 hemichannels permeable to $\mathrm{Ca}^{2+}$ in transfected HeLa cells. Am. J. Physiol. Cell Physiol. 297, C665-C678. doi: 10.1152/ajpcell.00200.2009

Schalper, K. A., Palacios-Prado, N., Orellana, J. A., and Sáez, J. C. (2008). Currently used methods for identification and characterization of hemichannels. Cell Commun. Adhes. 15, 207-218. doi: 10.1080/15419060802014198

Schalper, K. A., Sánchez, H. A., Lee, S. C., Altenberg, G. A., Nathanson, M. H., and Sáez, J. C. (2010). Connexin 43 hemichannels mediate the Ca2+ influx induced by extracellular alkalinization. Am. J. Physiol. Cell Physiol. 299, C1504-C1515. doi: 10.1152/ajpcell.00015.2010

Stout, C. E., Costantin, J. L., Naus, C. C., and Charles, A. C. (2002). Intercellular calcium signaling in astrocytes via ATP release through connexin hemichannels. J. Biol. Chem. 277, 10482-10488. doi: 10.1074/jbc.M1099 02200

Taylor, K. A., Wright, J. R., and Mahaut-Smith, M. P. (2015). Regulation of Pannexin-1 channel activity. Biochem. Soc. Trans. 43, 502-507. doi: 10.1042/BST20150042

Trexler, E. B., Bennett, M. V., Bargiello, T. A., and Verselis, V. K. (1996). Voltage gating and permeation in a gap junction hemichannel. Proc. Natl. Acad. Sci. U.S.A. 93, 5836-5841.

Valiunas, V. (2002). Biophysical properties of connexin-45 gap junction hemichannels studied in vertebrate cells. J. Gen. Physiol. 119, 147-164. doi: 10.1085/jgp.119.2.147

Valiunas, V., and Weingart, R. (2000). Electrical properties of gap junction hemichannels identified in transfected HeLa cells. Pflugers Arch. 440, 366-379. doi: $10.1007 / \mathrm{s} 004240000294$

Van Rijen, H. V., Wilders, R., Van Ginneken, A. C., and Jongsma, H. J. (1998). Quantitative analysis of dual whole-cell voltage-clamp determination of gap junctional conductance. Pflugers Arch. 436, 141-151. doi: $10.1007 /$ s004240050615

Verselis, V. K., and Srinivas, M. (2013). Connexin channel modulators and their mechanisms of action. Neuropharmacology 75, 517-524. doi: 10.1016/j.neuropharm.2013.03.020

von Maltzahn, J., Euwens, C., Willecke, K., and Söhl, G. (2004). The novel mouse connexin39 gene is expressed in developing striated muscle fibers. J. Cell Sci. 117(Pt 22), 5381-5392. doi: 10.1242/jcs.01413

von Maltzahn, J., Wulf, V., Matern, G., and Willecke, K. (2011). Connexin39 deficient mice display accelerated myogenesis and regeneration of skeletal muscle. Exp. Cell Res. 317, 1169-1178. doi: 10.1016/j.yexcr.2011.01.017

Yap, C. W. (2011). PaDEL-descriptor: an open source software to calculate molecular descriptors and fingerprints. J. Comput. Chem. 32, 1466-1474. doi: $10.1002 /$ jcc. 21707

Zonta, F., Mammano, F., Torsello, M., Fortunati, N., Orian, L., and Polimeno, A. (2014). Role of gamma carboxylated Glu47 in connexin 26 hemichannel regulation by extracellular $\mathrm{Ca}(2)(+)$ : insight from a local quantum chemistry study. Biochem. Biophys. Res. Commun. 445, 10-15. doi: 10.1016/j.bbrc.2014.01.063

Zonta, F., Polles, G., Sanasi, M. F., Bortolozzi, M., and Mammano, F. (2013). The 3.5 angstrom X-ray structure of the human connexin26 gap junction channel is unlikely that of a fully open channel. Cell Commun. Signal. 11:15. doi: $10.1186 / 1478-811 X-11-15$

Conflict of Interest Statement: The authors declare that the research was conducted in the absence of any commercial or financial relationships that could be construed as a potential conflict of interest.

Copyright (c) 2017 Vargas, Cisterna, Saavedra-Leiva, Urrutia, Cea, Vielma, Gutierrez-Maldonado, Martin, Pareja-Barrueto, Escalona, Schmachtenberg, Lagos, Perez-Acle and Sáez. This is an open-access article distributed under the terms of the Creative Commons Attribution License (CC BY). The use, distribution or reproduction in other forums is permitted, provided the original author(s) or licensor are credited and that the original publication in this journal is cited, in accordance with accepted academic practice. No use, distribution or reproduction is permitted which does not comply with these terms. 